\title{
Fire Size and Fire Spread in Tunnels with Longitudinal Ventilation Systems.
}

\author{
Journal of Fire Sciences, Volume 23 (2005), pp. 485-518. \\ R.O. Carvel ${ }^{*}$, A.N. Beard \& P.W. Jowitt \\ School of the Built Environment, William Arrol Building \\ Heriot-Watt University, Edinburgh EH14 4AS, Scotland, UK
}

D.D. Drysdale

Institute for Infrastructure and the Environment, Faraday Building

University of Edinburgh, Edinburgh EH9 3JL, Scotland, UK

\begin{abstract}
The results and findings of three previous research projects are combined with new research to estimate the overall influence of longitudinal ventilation on fire size and spread in tunnels. Each of the three previous projects is briefly described. Combining the results of these three projects, together with knowledge of HGV fire behaviour in an experimental test, enables the estimation of the maximum fire size of a fire in a tunnel and the conditions under which it might spread to an adjacent vehicle, for a given longitudinal ventilation velocity. These results have been combined into a single computer model. Results are presented and discussed. It is concluded that, although it may greatly increase the heat release rate of a fire in a tunnel, increasing the ventilation velocity will tend to reduce the likelihood of the fire spreading to an adjacent vehicle, assuming no flame impingement.
\end{abstract}

Key words: $\quad$ Fire size, Heat Release Rate, Fire spread, Longitudinal ventilation, Probabilistic model

* Corresponding author.

* Tel: +44 (0) 131451 4410. Fax: +44 (0) 1314514617 . e-mail: ricky@ tunnelfiresafety.co.uk 


\section{INTRODUCTION}

The need for better and more efficient transport systems is increasing world-wide. In many places, particularly in some parts of Europe and the Far East, the restrictions imposed by the local geography and by already intensive land use mean that the only available space for improved transport systems is underground. In the past decade more tunnels have been planned and built than in any previous decade and the length of modern tunnels is ever increasing. Although serious fires in tunnels are rare, the recent fires in the Daegu underground (more than 190 fatalities and two trains destroyed) [1], the St Gotthard road tunnel (eleven fatalities and 23 vehicles destroyed) [2] and the funicular railway tunnel at Kaprun (155 fatalities and the train destroyed) [3] have shown the devastating effect that fires can have in tunnels and underground spaces.

In the event of a fire, most tunnel safety management systems rely on an emergency ventilation system to control or extract the smoke to maintain a smoke free route of escape. There are three main types of tunnel ventilation systems:

1. Fully transverse ventilation - fresh air is supplied to the tunnel through vents positioned at regular intervals along the tunnel's length, these are opposed by exhaust air vents to extract pollutants etc. from the tunnel.

2. Semi-transverse ventilation - fresh air is supplied through periodic vents as in the previous case, however, in this case the exhaust air is extracted through only one or two large vents, usually at or near each of the main portals.

3. Longitudinal ventilation - fresh air is forced along the length of the tunnel, generally by jet fans mounted on the roof. This system is often to be found in vehicle tunnels with uni-directional traffic, and is sometimes used as a supplementary emergency system for transversely ventilated tunnels.

The majority of tunnels in the USA have transverse ventilation systems with only a small number of recently built tunnels being equipped with longitudinal ventilation. In the Far East, especially Japan, the majority of tunnels are longitudinally ventilated. In Europe both longitudinal and transverse ventilation systems are common. Hybrid systems, comprised of transverse supply and extract ducts combined with jet fans in the vehicle space to control longitudinal ventilation flow, are also now being considered for new and refurbished tunnels [4]. It should be noted that many existing tunnel ventilation systems have been constructed assuming a 'design fire' 
of between 20 and 50MW, based on some early estimates of the burning rate of a HGV. It will be demonstrated in this paper that fires of this magnitude may be unrealistically small and hence many existing ventilation systems may be unable to sufficiently control or extract smoke from real HGV fire incidents.

A number of experimental studies have been carried out to determine the effectiveness of these different ventilation systems in controlling and extracting smoke in the event of a fire; of these the Memorial Tunnel Fire Ventilation Test Programme (MTFVTP) [5] was the most comprehensive. However, the majority of these studies did not consider the effect of the ventilation system on the behaviour of the fire itself.

The burning behaviour of any fire in a confined space is dependent on the ventilation conditions in that space. Forced ventilation in a tunnel can have a number of different and conflicting effects on a fire. It will bring with it a plentiful supply of oxygen which will tend to increase the severity of the blaze, but it will also have a cooling effect which may tend to reduce the severity. It may cause the fire to spread across the load at a significantly faster or slower rate, it could even put the fire out entirely. It may also help or hinder the progression of the fire as it spreads from one vehicle to another. To date, the relative importance of each of these factors has not been adequately investigated.

The heat release rate (HRR) is considered by many to be the most important factor contributing to the severity of a fire [6]. Previous research has shown that, for a heavy goods vehicle (HGV) fire in a tunnel, increasing the longitudinal ventilation rate in the tunnel can have a significant enflaming effect on the fire, increasing the HRR dramatically $[7,8,9]$. Other research (leading to the "FIRE-SPRINT" models, described below) has shown that, for a given tunnel size, ventilation rate and vehicle spacing, there exists a critical HRR above which a fire will spread from one HGV to an adjacent one $[10,11,12]$. This critical HRR is generally predicted to have higher values at higher airflow velocities (assuming that the degree of flame impingement on the second object, if any, does not vary with ventilation velocity). The predicted critical HRR values have been found to be considerably lower if flame impingement is assumed than if no impingement is assumed [13]. The most recent version of the model which assumes no flame impingement is FIRE-SPRINT A3 [12]. The most recent version which assumes a small, but persistent, degree of flame impingement is FIRE-SPRINT B1 [13]. The assumption that the degree of impingement does not vary with ventilation velocity may well not be realistic and it is hoped to be able to amend it in future development of the model, as data and understanding allow. 
Until now it has not been known whether the increase in HRR of a HGV fire, due to the enflaming effect of increased airflow velocity, is larger or smaller than the increase in the critical HRR value at higher airflow velocities. In other words, until now it has not been known whether increasing the longitudinal ventilation rate in a tunnel will tend to assist or hinder the propagation of the fire from one HGV to an adjacent one.

In the St Gotthard fire incident (2001), the fire spread from the initial two vehicles involved in the crash to involve seven heavy goods vehicles (other vehicles in the tunnel were damaged because of the intense heat and thick deposits of soot, but were not directly involved in the fire) [14]. In the incident in the Mont Blanc tunnel (1999), the fire spread from the original HGV on fire to involve 34 vehicles (23 HGVs, 9 cars, a van and a motorcycle) [15]. If fire spread from vehicle to vehicle can be prevented, or at least hindered, by informed control of a tunnel ventilation system, we may move one step closer to being able to prevent this scale of disaster in the future.

\section{THE INFLUENCE OF VENTILATION ON THE HEAT RELEASE RATE OF A HGV FIRE}

\section{The Results of the Original Study}

From 1998 to 2000, a research project was carried out to investigate the influence of longitudinal ventilation on fire size (HRR) for fires in tunnels [9]. The project investigated five different cases: fires involving HGVs, passenger cars and three different sizes of pool fires. The study was probabilistic in nature, producing a probability distribution of fire size for each of the cases at four different longitudinal ventilation velocities $(2,4$, $\left.6 \& 10 \mathrm{~ms}^{-1}\right)$. The fire size is defined in terms of the coefficient $k$, defined by:

$$
Q_{\text {vent }}=k Q_{\text {nat }}
$$

where $Q_{\text {vent }}$ is the heat release rate of a fire in a tunnel with longitudinal ventilation of a specified airflow velocity and $Q_{n a t}$ is the heat release rate of a similar fire in a similar tunnel subject to only natural ventilation. In this way particular uncertainties relating to the exact nature of the burning object (HGV cargo, pool composition, etc.) can 
be avoided. If a car would burn at $2 \mathrm{MW}$ in a naturally ventilated tunnel and $k$ has a value of about 3 under certain ventilation conditions, then we would expect such a car to burn at 6MW. However, a different car might burn at $1.3 \mathrm{MW}$ in a naturally ventilated tunnel, this car could be expected to burn at about $4 \mathrm{MW}$ under the same ventilation conditions, and so on.

The study used Bayesian methods to estimate the probability distribution of $k$ for each case at each of the ventilation velocities of interest in a tunnel similar to the Channel Tunnel. Bayesian methods were used because there simply are not enough experimental data available to estimate the relationship between ventilation velocity and $k$ by a conventional statistical analysis. Bayes' Theorem is an established scientific method for making decisions or accurate estimates based on limited evidence. For further details of Bayes' Theorem see references 7-9.

An initial probability distribution was devised, based on the estimates of a panel of experts in the fields of tunnel fire safety and fire safety engineering. In Bayesian terminology, this is known as the 'prior' probability distribution. The mean value of the probability distribution, known as the 'expectation', is generally taken to be a good estimate of the value of $k$ at any given ventilation velocity. Graphical representations of the expectation of $k$ and the prior probability distribution data are given in Figure 1 . The derivation of the continuous probability percentiles shown in Figures 1, 2 and 5 is discussed in detail below.

In the discussion that follows, the phrase 'full scale' will be used to denote ventilation velocities and heat release rates which have been scaled up to the values they would have in a tunnel similar in size and shape to the Channel Tunnel. The data have been scaled up such that the Froude number is the same for both the full scale and reduced scale tunnels. In this manner the airflow velocities scale according to $L^{\frac{1}{2}}$, where $L$ is a characteristic dimension of the tunnel, and the heat release rates scale according to $L^{\frac{5}{2}}[16]$. Note that $k$, being a ratio of two heat release rates, is the same at full scale and reduced scale. Studies have identified the mean hydraulic diameter of a tunnel to be an appropriate characteristic dimension to use when comparing tunnels of different shapes [17], so this is the length scale used in this study.

When the project was carried out, only five tunnel fire experiments were deemed to give any information on the behaviour of a HGV fire in a tunnel, these were: 
- $\quad$ The HGV fire test carried out in an abandoned tunnel near Hammerfest, Norway in 1992 [18]

- The "simulated truck load" fire test carried out in the Hammerfest tunnel in 1992 [19]

- The reduced scale $(1: 3)$ simulation of a HGV fire on a Channel Tunnel shuttle carried out in the fire gallery of the Health \& Safety Laboratory (HSL), Buxton, UK in 1994 [20]

- $\quad$ The wooden crib fire test carried out in the Health \& Safety Laboratory fire gallery in 1994 [21]

- The large wooden crib fire tests carried out by FOA in a "blasted rock tunnel" in Sweden in 1997 [22]

Comparing these experimental data gives three pieces of evidence which can be used to 'update' the prior probability distributions.

1. The Hammerfest HGV test (forced ventilation equivalent to 6.9 and $3.3 \mathrm{~ms}^{-1}$ at full scale) compared with the Hammerfest simulated truck load (natural ventilation)

2. The HSL HGV simulation test (forced ventilation equivalent to $6.4,2.5$ and $1.7 \mathrm{~ms}^{-1}$ at full scale) compared with the Hammerfest simulated truck load (natural ventilation)

3. The HSL wooden crib fire test (forced ventilation equivalent to $2.0 \mathrm{~ms}^{-1}$ at full scale) compared with FOA wooden crib tests (natural ventilation)

Bayesian methods were then used to update each of the prior estimates, in the light of the first piece of experimental evidence, to give the "posterior" probability distributions. These first posterior distributions were then updated in the light of the second piece of experimental evidence to give a second set of posterior distributions. This process was repeated for the third piece of experimental evidence.

The final posterior probability distributions indicate that the HRR of a HGV will be greatly enhanced by longitudinal ventilation; there is a high probability that a HGV fire, in a tunnel similar to the Channel Tunnel, will have a HRR about five times greater with a forced ventilation velocity of $4 \mathrm{~ms}^{-1}$ than with natural ventilation. Similarly there is a high probability that a HGV fire will have a HRR about ten times greater with a forced ventilation velocity of $10 \mathrm{~ms}^{-1}$ than with natural ventilation [7,8]. Graphical representations of the expectation of $k$ and the final posterior probability data for a HGV fire, from the original study, are shown in Figure 2. 
The study also predicted that forced ventilation will have an enflaming effect on small to medium sized pool fires at low ventilation rates, but that higher ventilation velocities will tend to reduce the HRR of the fire. On the other hand, for large pool fires, forced ventilation appears to have an enflaming effect at all ventilation rates [8]. The study did not show significant variation of the HRR of car fires with forced ventilation. The influence of longitudinal ventilation on fires other than HGV fires will not be considered further in this paper.

\section{The Results Updated}

In the years since the completion of the original project, two series of fire experiments in tunnels have been carried out which have produced data which can be used to update the Bayesian estimates. These series were:

- The "HGV load" fire tests carried out in the $2^{\text {nd }}$ Benelux Tunnel, Rotterdam, The Netherlands, 2002 [23].

- The "HGV trailer" fire tests carried out in the Runehamar Tunnel, Norway, 2003 [24].

Although both these test series were carried out in two-lane tunnels, they can be used to update the Bayesian estimates of the influence of ventilation on HGV fires in a tunnel similar to the Channel Tunnel. The Runehamar tunnel is small for a two lane tunnel and is actually similar in size (width, cross-sectional area) to the Channel Tunnel, so there is a direct correlation between these two tunnels. While the cross-section of the $2^{\text {nd }}$ Benelux tunnel is significantly larger than that of the Channel Tunnel, the fire tests carried out in it may also be used to update the single-lane tunnel estimates. In these updates it is assumed that the influence of air at a given ventilation velocity will not be smaller in the single lane tunnel scenario than it was in the two-lane tunnel experiments, although it may be larger.

The relevant fire tests from each test series will now be briefly described.

\section{Fire Tests Carried out in the $2^{\text {nd }}$ Benelux Tunnel, 2002}

A series of sixteen full scale fire tests were carried out in tube D of the new 2nd Benelux tunnel, Rotterdam, the Netherlands, shortly before the tunnel was opened to traffic in 2002. The test series included six pool fire tests, three car fire tests, a van fire test, three "HGV load" fire tests with a canvas covering, three "HGV load" fire 
tests with an aluminium covering and a very large fire test with wooden pallets. Some of these tests were carried out with natural ventilation and some with forced ventilation at 3 and $6 \mathrm{~ms}^{-1}$.

Tube D of the 2nd Benelux tunnel has an approximately rectangular cross-section. It is $9.8 \mathrm{~m}$ wide and $5.1 \mathrm{~m}$ high, see Figure 3 . The fire tests were all carried out on a platform on the right hand carriageway of the tunnel.

From the tests carried out in the tunnel, two pieces of evidence can be derived to update the probability estimates of $k$ for a fully involved HGV fire:

- HGV load fire test 8 (natural ventilation) compared with HGV load fire test 9 (forced ventilation at $6 \mathrm{~ms}^{-1}$ )

- HGV load fire test 8 (natural ventilation) compared with HGV load fire test 10 (forced ventilation at $6 \mathrm{~ms}^{-1}$ )

Three fire tests were carried out with a "mock-up" of a HGV trailer with a canvas covering. The canvas hood measured $4.5 \mathrm{~m}$ long by $2.4 \mathrm{~m}$ wide by $2.5 \mathrm{~m}$ high, the back of the hood was open. The cargo in each test consisted of four stacks of 9 wooden pallets with a car tyre on the top of each stack (to generate more smoke), in each test the cargo was ignited by means of a small bowl of petrol placed at the centre of the load. One test (test 8) was carried out with natural ventilation and two tests (tests $9 \& 10$ ) were carried out with forced ventilation at $6 \mathrm{~ms}^{-1}$. The naturally ventilated test reached a peak HRR of about $13.5 \mathrm{MW}$ about 17 minutes after ignition. The forced ventilation tests ultimately reached peak HRRs of $19.5 \mathrm{MW}$ and $16.5 \mathrm{MW}$ after 7 and 8 minutes respectively. From this it is clear that $k$ for the fully involved fire was about 1.4 for test 9 and 1.2 for test 10 for a forced ventilation rate of $6 \mathrm{~ms}^{-1}$.

\section{Fire Tests Carried out in the Runehamar tunnel, 2003}

A series of four full scale fire tests were carried out in an abandoned tunnel in Norway in September 2003. The interior of the two lane tunnel has a rough rock surface for most of its length, but a section of the tunnel was lined with protective cladding for the purposes of the tests. The fire tests were carried out in the lined section which was approximately $7.5 \mathrm{~m}$ wide by $5 \mathrm{~m}$ high, see Figure 4 . 
Each of the four tests involved a fire load equivalent in size and shape to a HGV trailer. In test 1 the cargo was 9.9 tonnes of wooden pallets and plastic materials, in test 2 the cargo was 6.1 tonnes of wooden pallets and mattresses, in test 3 the cargo was 7.7 tonnes of furniture (and some tyres) and in test 4 the cargo was 2.6 tonnes of plastic cups in cardboard boxes on pallets. In each test the percentage of plastic materials was estimated to be about $18-20 \%$ of the total load.

Longitudinal ventilation was supplied by two large fans positioned at the western end of the tunnel. Before each test the ventilation flow in the tunnel was about $3 \mathrm{~ms}^{-1}$ but this reduced to about $2-2.5 \mathrm{~ms}^{-1}$ once each fire became fully involved. Full details of the fire tests can be found in [24].

Unfortunately, for the purposes of this study, there was no naturally ventilated fire test carried out in the Runehamar tunnel. Some open air fire tests of small quantities of the fire loads were carried out, but it is not really possible to predict the fire behaviour of equivalent naturally ventilated fires in tunnels from these data. Therefore the Runehamar data from fire tests with forced ventilation have been compared to the largest naturally ventilated wooden crib test carried out in the $2^{\text {nd }}$ Benelux tunnel.

The first fire test in the Runehamar tunnel, comprised of 9.9 tonnes of wooden pallets and plastic materials, reached a peak HRR of about 220MW after about 15 minutes. Estimating $k$ for the fully involved fire is slightly problematic; the fire load in the Runehamar tunnel test 1 was about six times larger (in terms of the mass of fuel) than the largest test carried out in the Benelux tunnel, which had a peak HRR of about 26MW. If one were to assume that a fire load six times larger in a naturally ventilated tunnel would have a peak HRR six times greater, then the value of $k$ for the peak HRR would be 1.4. However, it is unlikely that the peak HRR under these circumstances would be as high as six times as great, so assuming a $k$ value of about 2 for a ventilation velocity of about $2 \mathrm{~ms}^{-1}$ is not unreasonable.

The second fire test in this tunnel, comprised of 6.1 tonnes of wooden pallets and mattresses, reached a peak HRR of about $170 \mathrm{MW}$ after about 11 minutes. In a similar manner to the estimates for test 1 , above, it has been estimated that the value of $k$ at peak HRR is about 2, possibly higher. 
The third fire test in this tunnel, comprised of 7.7 tonnes of furniture, reached a peak HRR of about 140MW after about 8 minutes. In a similar manner to the estimates made above, it has been estimated that the value of $k$ at peak HRR is between 1 and 2, possibly higher.

The final fire test in this tunnel, comprised of 2.6 tonnes of plastic cups in cardboard boxes, reached a peak HRR of about $80 \mathrm{MW}$ after about three minutes. In a similar manner to the estimates made above, it has been estimated that the value of $k$ at peak HRR is larger than 2 .

As each of these four fire tests were only carried out at low ventilation velocities, they do not give much information regarding the influence of higher longitudinal ventilation rates on fires in tunnels. When using these data to update the calculations for 6 and $10 \mathrm{~ms}^{-1}$, the only assumption made is that the higher ventilation rates will not have less of an enflaming influence than $2-3 \mathrm{~ms}^{-1}$ airflows exhibit.

The posterior results from the original study were updated using estimates of likelihood based on these six pieces of evidence.

The updated posterior probability distributions indicate that the HRR of a HGV will be greatly enhanced by longitudinal ventilation; there is a high probability that a HGV fire, in a tunnel similar to the Channel Tunnel, will have a HRR about three times greater with a forced ventilation velocity of between 2 and $4 \mathrm{~ms}^{-1}$ than with natural ventilation. Similarly there is a high probability that a HGV fire will have a HRR about eight times greater with a forced ventilation velocity of $10 \mathrm{~ms}^{-1}$ than with natural ventilation. Graphical representations of the updated results for the expectation value of $k$ and the final posterior probability data for a HGV fire are shown in Figure 5.

The results for small pool fires and car fires have also been updated since the end of the original project [25].

\section{The Derivation of the Continuous Percentile Graphs}

The study of the influence of longitudinal ventilation on fire size for fires in tunnels produced discrete probability distributions of fire size at $2,4,6$ and $10 \mathrm{~ms}^{-1}$. These probabilities were calculated for $k$ ranges of 
$0.5-1,1-2,2-4,4-8,8-16,16-32,32-64$, and 64+. These data are presented in Figure 6 . In order to render all the data in a meaningful way on a single graph, the following method was used.

As the $k$ ranges are equally spaced on the log scale, calculations were carried out for ranges of $n$, where $k=2^{n}$. Thus the ranges of interest become $n=-0.5 \pm 0.5,0.5 \pm 0.5,1.5 \pm 0.5, \ldots 5.5 \pm 0.5$ and $6.5 \pm 0.5$. For each ventilation velocity, the probability data were expressed as cumulative probability functions, as shown in Figure 7 using the example of a HGV fire at $6 \mathrm{~ms}^{-1}$.

To generate the data for the percentile graphs, the values of $n$ corresponding to probability values of $0.1,0.3,0.5$, 0.7 and 0.9 on each graph were used. These were plotted on a graph of ventilation velocity vs. $k$ and the "smoothing" feature of the plotting software (Axum) was used to infer the points between the calculated velocities. By definition, $k$ equals unity at $0 \mathrm{~ms}^{-1}$ ventilation velocity.

\section{THE INFLUENCE OF VENTILATION ON FIRE SPREAD BETWEEN HGVS}

A project investigating the influence of longitudinal ventilation on fire spread between vehicles in tunnels has been ongoing since 1993. The project uses the concepts of non-linear dynamical systems theory to predict the critical value of HRR required before fire will spread from one vehicle to an adjacent one. The project has the generic title 'FIRE-SPRINT', an acronym for 'Fire Spread in Tunnels', and has produced two series of models: the 'A' series, which assumes that flame impingement does not take place on the target object, and the 'B' series, which assumes that there is a small, persistent, flame impingement on the target object.

\section{FIRE-SPRINT A3}

The most recent version of the 'A' series model, FIRE-SPRINT A3, assumes that the tunnel has "sides" and a "ceiling" which form a partial circle, as shown in Figure 8. It is assumed that there is a burning object (e.g. a vehicle) in the tunnel and that the longitudinal ventilation pushes all the smoke to one side of the fire, partially or wholly surrounding a rectangular cuboidal target object (analogous to a HGV trailer). Flame is assumed to extend beyond the downstream edge of the fire and go over the target object. In FIRE-SPRINT A3 it is assumed 
that the flame does not impinge directly on the target object, the implications of this assumption will be considered in the discussion section of this paper. A related model, FIRE-SPRINT B1, which assumes flame impingement exists on the target object is currently in development, see below [13].

The main part of the model consists of a control volume (CV), indicated by the dashed lines in Figure 8, which the hot gases enter and leave. For the purpose of calculating gas emissivities, the control volume is regarded as consisting of three parts: part S1 contains the gases between the sides of the target object and the tunnel walls, part S2 contains the gases directly above the target object and below the flame section, part S3 contains the gases in front of the target object and downstream of the edge of the initial fire. Three emissivities have been calculated corresponding to these three parts of the CV.

Some of the assumptions of the model are as follows. The forced ventilation produces an airflow with velocity $v$, parallel to the axis of the tunnel; this ventilation rate is assumed to be uniform over the tunnel cross-section and the inflowing air is assumed to be at ambient temperature. The ventilation forces all the smoke from the fire in the direction of flow; no smoke is assumed to move upstream. The flame from the fire is assumed to extend downstream of the fire, adjacent to the ceiling above the CV. It is assumed to be deeper before the target object than it is above the object. The base of the flame is horizontal and it is assumed that the flame extends downstream beyond the extent of the control volume.

The fire object and the rectangular cuboidal target object are assumed to be stationary in the tunnel. All the hot gases from the fire enter the control volume at one end and leave at the other end, no hot gases are assumed to be lost through the base of the CV. Within the CV, the hot gases are assumed to be of uniform temperature, T, and density, $\rho$. The hot gases lose energy to the walls and the target object. The initial fire has a fixed, user specified, value for its un-enhanced fuel mass loss rate, $\mathrm{M}_{\mathrm{f} u n}$; however, it is assumed that there is radiative feedback from the hot gases in the $\mathrm{CV}$ to the initial fire, which enhances the mass loss rate.

The principles of conservation of energy and mass have been applied to the control volume. For any particular case the equilibrium points for the system may be calculated using the conservation equations. Each equilibrium point corresponds to a value of $\mathrm{T}$ for each assumed value of $\mathrm{M}_{\mathrm{f} u n}$. The eigenvalues of a system provide numerical measures associated with the stability of that system. In simple terms, when the real part of an eigenvalue has a 
negative value the system is stable, when it has a positive value the system is unstable. The model calculates the eigenvalue associated with each equilibrium point and, hence, inferences can be drawn about the nature and stability of the system. The onset of instability in the system is associated with the sudden increase of the temperature of the gases in the control volume. It is assumed that this will result in the sudden spread of fire from the initial fire to the target object.

When carrying out a simulation, a succession of equilibrium points may be found which correspond to a succession of values of the parameter $\mathrm{M}_{\mathrm{fun}}$. The lowest value of $\mathrm{M}_{\mathrm{f} u n}$ which corresponds to a non-negative eigenvalue may be considered to relate to the critical HRR above which the fire will spread. Some sample results from the model will be presented later in the paper. For a more detailed description of FIRE-SPRINT A3, see reference [12]. Full details and sample simulations using the previous versions of the model, FIRE-SPRINT A2 and FIRE-SPRINT A1 may be found in references [10,11].

\section{FIRE-SPRINT B1}

FIRE-SPRINT B1 is similar to the model described above except that it also considers a narrow, rectangular cuboidal 'tongue' of flame which protrudes into the smoke section from the upper flame section and impinges onto the top corner of the target object. The model considers a second, very small, control volume, $\mathrm{CV}_{2}$, which exists between the flame and the target object at the point of impingement. The impinging flame is assumed to be persistent, not intermittent.

Generally, the critical HRR for fire spread assuming flame impingement (i.e. using FIRE-SPRINT B1) is considerably lower than the critical HRR for fire spread assuming no flame impingement (i.e. using FIRESPRINT A3). Some sample results from the model will be presented later in the paper. For a more detailed description of FIRE-SPRINT B1, see reference [13].

\section{THE INFLUENCE OF TUNNEL GEOMETRY ON FIRE SIZE IN TUNNELS}

A third project, carried out from 2000 to 2001, investigated the influence of tunnel geometry on the heat release rate of a fire. An extensive literature study [26] identified a number of naturally ventilated tunnel fire 
experiments where the peak heat release rate of the fire was significantly greater than the heat release rate of similar, open air, fire experiments. The apparent enhancement was attributed to the effects of the tunnel geometry. The study also identified a small number of naturally ventilated tunnel fire experiments where the HRR was significantly lower than in similar, open air, experiments. In this instance the reducing effect was attributed to insufficient oxygen to feed the fire. At present, there do not appear to be enough experimental data to investigate the relationship between tunnel geometry and fire size in the oxygen-depleted regime.

It was observed that, under certain geometrical conditions, a naturally ventilated fire in a tunnel could have a peak HRR up to four times greater than a similar fire in the open air [26]. This enhancement could be further increased by the influence of longitudinal ventilation, as described above. Throughout the project the coefficient $\psi$ was used to describe the HRR enhancement, this is defined by:

$$
Q_{\text {tun }}=\psi \cdot Q_{\text {open }}
$$

where $Q_{t u n}$ is the HRR of a naturally ventilated fire in a tunnel and $Q_{\text {open }}$ is the HRR of a fire in the open air.

A Bayesian decision methodology was used to determine which geometrical factor (e.g. width, height, aspect ratio, blockage ratio, etc.) has the most significant influence on $\psi$. The results suggested that the width of a tunnel has significantly more influence over the degree of HRR enhancement than any other geometrical factor [26]. (The height of a tunnel is also of significance, but the study found that width was more important.) Having established this, it was a fairly straightforward process to estimate the relationship between tunnel width and HRR enhancement.

This relationship was found to be:

$$
\psi=24\left(\frac{W_{f}}{W_{t}}\right)^{3}+1
$$


where $W_{f}$ is the width of the fire source and $W_{t}$ is the width of the tunnel. In many instances it may be desirable to consider the additional HRR due to being in a tunnel, this can be easily estimated by rearranging Equations (2) and (3) to give:

$$
Q_{a d d}=24 \cdot Q_{o p e n}\left(\frac{W_{f}}{W_{t}}\right)^{3}
$$

where $Q_{a d d}$ is the additional HRR due to the enhancement of the fire by the tunnel (thus the actual heat release rate of the fire in the tunnel is given by $\left.Q_{\text {tun }}=Q_{\text {open }}+Q_{a d d}\right)$.

This relationship appears to hold for heptane, kerosene and xylene pool fires, wooden crib fires and car fires, where the width of the fire object is less than half the width of the tunnel. Although there are, at present, no data for naturally ventilated HGV fires in tunnels or for HGV fires in the open air, it is assumed that the relationship also holds for HGVs. The relationship does not hold for methanol pool fires, which exhibit significantly different burning behaviour from most other common fuels, and it appears that it may slightly under-predict HRR values in tunnels with concave ceilings [27].

\section{THE UNIFIED MODEL}

The three projects described above are essentially parts of a larger ongoing project which aims to adequately describe the size and spread of a fire in a tunnel. Integral to this larger project is the necessity of combining all the different strands of research into a single unified model. The unified model has been named 'CERBERUS' after the three headed dog which was the guardian at the entrance to the underworld in ancient Greek mythology ${ }^{\dagger}$. In this instance, CERBERUS is an acronym for Computer Estimate of the Rate of $\underline{B}$ laze Enlargement and Risk of $\underline{\text { Underground }}$ Spread. The model, like the mythical dog, is three headed; it combines elements of each of the three separate research projects, described above.

\footnotetext{
$\dagger$ The 'CERBERUS' model is not connected with the Cerberus division of Seimens Building Technology in any way.
} 
The results from these projects have been combined into the unified model CERBERUS A1.2 $2^{\ddagger}$ By combining these results into a single model the whole picture of fire size and spread in a tunnel, under specified ventilation and geometrical conditions, becomes clearer.

The CERBERUS model takes the HRR characteristics of a HGV fire in the open air (see below) as its starting point. The model then makes calculations to account for ventilation and tunnel size and produces a probability distribution for the peak HRR of a HGV fire in a ventilated tunnel of interest. The model also predicts the critical HRR necessary for the fire to jump to an adjacent vehicle (a user-specified distance away). Finally, the model calculates the percentage probability of the peak HRR being above the critical HRR and presents all the data in graphical form. Some sample outputs are presented and discussed below.

\section{THE HRR OF A HGV IN THE OPEN AIR}

To date, the only well documented fire test of an actual HGV was carried out in the abandoned mine tunnel near Hammerfest, Norway on $12^{\text {th }}$ November 1992 [18]. No HGV fire experiments have been carried out in the open air or in larger tunnels. In order to estimate the burning behaviour of a HGV in the open air it is necessary to use these data and adjust for the enhancement due to the tunnel and forced ventilation.

The HGV used in the Hammerfest test was a Leyland DAF 310ATi. The trailer was 12.2m long, 2.4m wide and $2.5 \mathrm{~m}$ high, it was filled with about two tonnes of furniture and covered with a tarpaulin. It was estimated that the total fire load of the $\mathrm{HGV}$ and cargo was $87400 \mathrm{MJ}$, of which $42750 \mathrm{MJ}$ was due to the furniture. The Hammerfest tunnel is $2.3 \mathrm{~km}$ long, less than $1^{\circ}$ off horizontal and has a cross-section roughly in the shape of a flattened horseshoe. The cross-sectional area of the tunnel is $34 \mathrm{~m}^{2} \pm 4 \mathrm{~m}^{2}$. The HGV was located $295 \mathrm{~m}$ from the north end of the tunnel, facing north. Ventilation was provided by fans at the north end of the tunnel. Temperature, airflow velocity, gas concentration and other measurements were made at a number of locations in the tunnel, both upwind and downstream of the fire location.

\footnotetext{
${ }^{\ddagger}$ The earlier version of the model, CERBERUS A1.1, is similar to the model described here, but was developed before the updates to the Bayesian longitudinal ventilation study were carried out.
} 
At the start of the fire test, the fans were set to maximum speed. This generated an airflow velocity of $6 \mathrm{~ms}^{-1}$ upstream of the HGV and approximately $10-16 \mathrm{~ms}^{-1}$ around the HGV trailer. After 13.5 minutes the fans were switched off and restarted at a lower speed after a further 3 minutes, the resulting airflow was between 2 and $3.8 \mathrm{~ms}^{-1}$ upstream of the fire. The temperature in the cab reached a maximum of about $1150^{\circ} \mathrm{C}$ after 10 minutes. Shortly after this the fire spread to the trailer and a maximum temperature of over $1100^{\circ} \mathrm{C}$ was recorded in the trailer about 18 minutes from the start of the test.

Different methods of calculating the heat release rate (HRR) of the fire were used. The Norwegian scientists involved with the test calculated that the fire reached a maximum HRR of over 300MW about 13 minutes after ignition. German scientists calculated a maximum HRR of about 190MW after 13 minutes whereas British scientists calculated the HRR to be $120 \mathrm{MW}$ after 13 minutes and as high as $128 \mathrm{MW}$ after 18 minutes [19]. The British calculated HRR was used in this study and the HRR time graph for the fire test is shown in Figure 9.

The first stage in adjusting the HRR profile is to compensate for the effects of ventilation. The probability distributions of $k$ for a HGV fire in a single lane tunnel similar to the Channel Tunnel at $2 \mathrm{~ms}^{-1}$ and $4 \mathrm{~ms}^{-1}$ are presented in Figure 5 and also in Table 1.

At present it is assumed that $k$ values in the Hammerfest tunnel would have been similar to $k$ values in a tunnel similar to the Channel Tunnel. The peak HRR of the Hammerfest HGV test was attained using a ventilation rate close to $3 \mathrm{~ms}^{-1}$, so the probability distribution for $k$ at $3 \mathrm{~ms}^{-1}$ has been assumed to be mid way between the probability distributions at 2 and $4 \mathrm{~ms}^{-1}$. The probabilities of $k$ in a single lane tunnel (Hammerfest or Channel Tunnel) at $3 \mathrm{~ms}^{-1}$ are shown in Table 1.

Therefore it is assumed that there is a $5.0 \%$ likelihood that a $3 \mathrm{~ms}^{-1}$ ventilation flow in a single lane tunnel would increase the HRR of a HGV fire by a factor between 1 and 2 (i.e. about one in $20 \mathrm{HGV}$ fires subject to a $3 \mathrm{~ms}^{-1}$ longitudinal ventilation would have a peak HRR between 1 and two times that of a naturally ventilated HGV fire). Also, there is a $76.9 \%$ likelihood that a $3 \mathrm{~ms}^{-1}$ ventilation flow in a single lane tunnel would increase the HRR of a HGV fire by a factor between 2 and 4 (i.e. about three out of four fires would have a peak HRR between 2 and 4 times that of a naturally ventilated $\mathrm{HGV}$ fire), and a $17.9 \%$ likelihood that a $3 \mathrm{~ms}^{-1}$ ventilation flow in a single lane tunnel would increase the HRR of a HGV fire by a factor between 4 and 8 . 
As the actual HRR of the HGV fire subject to $3 \mathrm{~ms}^{-1}$ airflow in the Hammerfest tunnel was about 128MW, it can be estimated that there is a $5.0 \%$ chance that the HRR of a HGV subject to natural ventilation (in the same tunnel) would be between 64 and 128MW, that is between 1 and 2 times smaller than the observed HRR. Similarly, there is a $76.9 \%$ chance that the HRR would have been between 32 and $64 \mathrm{MW}$ and a $17.9 \%$ chance that it would have been between 16 and 32MW. As the probability of the HRR being below 16MW is less than $0.2 \%$ it has been assumed, for simplicity in the model, that the HRR of a HGV fire in a naturally ventilated tunnel would not have been below 16MW.

The next stage in adjusting this HRR profile is to compensate for the confining geometry of the tunnel. By using Equation (3) it can be calculated that the HRR enhancement (of a $2.4 \mathrm{~m}$ wide HGV fire) due to the (5m wide) Hammerfest tunnel is

$$
\psi=24 \cdot\left(\frac{W_{F}}{W_{T}}\right)^{3}+1=24 \cdot\left(\frac{2.4}{5}\right)^{3}+1=3.65
$$

that is to say, the peak HRR of a similar fire in the open air would be expected to be just over a quarter of the peak HRR of this test. Thus, each of the HRR values quoted above for a HGV in a naturally ventilated tunnel should be divided by 3.65 to obtain the HRR values that would be obtained in the open air. These calculations have the effect of adjusting the x-axis of the probability graph of HRR by a factor of 3.65 . The probability distribution for HRR in the open air derived in this way is shown in figure 10.

Thus, the peak of the probability distribution for the HRR of a HGV fire in the open air, adjusted for geometry and ventilation, is estimated to be in the range $10-15 \mathrm{MW}$, while the probability distribution ranges from about $4 \mathrm{MW}$ to about $35 \mathrm{MW}$. The expectation or mean of the distribution is approximately $11 \mathrm{MW}$, the $10^{\text {th }}$ percentile is approximately $7 \mathrm{MW}$ and the $90^{\text {th }}$ percentile is approximately $17 \mathrm{MW}$.

The Hammerfest HGV fire test, on which the 'open air' HGV at the core of this model is based, was loaded with wooden framed furniture. This is a comparatively flammable cargo. In order to allow the CERBERUS user to model HGV fires with cargoes which have different properties from furniture, a 'cargo factor' has been included 
in the model. This cargo factor adjusts the peak HRR of the HGV at the core of the model; a cargo factor of 10 corresponds to the HGV loaded with furniture, a cargo factor of 5 corresponds to a vehicle with half the HRR of a HGV carrying furniture, and so on. The model user can choose a cargo factor appropriate for the situation they want to consider. 


\section{WHAT THE MODEL DOES}

Essentially, the CERBERUS model takes the data shown in Figure 10 as a starting point and applies certain rules (described below) to these data in order to predict the spread of HRR values for a HGV fire under given ventilation and geometrical conditions.

The preliminary version of the model described here only makes calculations for a tunnel similar in size and shape to the Channel Tunnel. Thus, the first step carried out by the model is to adjust the 'open air' probability distribution, shown in Figure 10, to give the probability distribution of HRR in a tunnel similar to the Channel Tunnel. For a HGV $2.4 \mathrm{~m}$ wide in the $7.6 \mathrm{~m}$ wide tunnel, the enhancement due to the geometry, $\psi$, is given by Equation (3):

$$
\psi=24 \cdot\left(\frac{W_{F}}{W_{T}}\right)^{3}+1=24 \cdot\left(\frac{2.4}{7.6}\right)^{3}+1=1.76
$$

That is to say, the values on the $\mathrm{x}$-axis of the HRR probability distribution for a HGV fire in the open air need to be adjusted (multiplied) by a factor of 1.76 to obtain the HRR probability distribution for a (naturally ventilated) HGV fire in a tunnel the size of the Channel Tunnel, as shown in Figure 11.

The model then generates a probability distribution of heat release rate for a HGV in a longitudinally ventilated, single lane, tunnel based on the results of the earlier probabilistic study. For example, consider a HGV subject to longitudinal ventilation at $4 \mathrm{~ms}^{-1}$ (the probability distribution of $k$ in a tunnel similar to the Channel Tunnel at $4 \mathrm{~ms}^{-1}$ is given in Table 1).

The probability distribution of HRR for a naturally ventilated HGV fire in a tunnel similar to the Channel Tunnel consists of only three ranges, each having a different estimate of probability. In the discussion that follows the range from 7.7 to $15.4 \mathrm{MW}$, which has a probability of $18 \%$, will be denoted 'range A', as shown in Figure 11. The range from 15.4 to $30.9 \mathrm{MW}$, which has a probability of $77 \%$, will be denoted 'range B' and the range from 30.9 to $61.7 \mathrm{MW}$, which has a probability of $5 \%$, will be denoted 'range C'. Each of these ranges makes a contribution to the overall probability distribution of fire size in a tunnel with longitudinal ventilation. 
The contribution of range A to the final probability distribution at $4 \mathrm{~ms}^{-1}$ can be calculated as follows. Table 1 shows that there is a $2.5 \%$ probability that $k$ will be between 1 and 2 for a $4 \mathrm{~ms}^{-1}$ airflow, thus part of the contribution of range $\mathrm{A}$ is that there is a $2.5 \% \times 18 \%=0.45 \%$ probability that the HRR of the longitudinally ventilated fire will be between $7.7(7.7 \times 1)$ and 30.9MW $(15.4 \times 2)$. Table 1 shows that there is a $62.4 \%$ probability that $k$ will be between 2 and 4 for a $4 \mathrm{~ms}^{-1}$ airflow, thus another part of the contribution of range A is that there is a $62.4 \% \times 18 \%=11.23 \%$ probability that the HRR of the longitudinally ventilated fire will be between $15.4(7.7 \times 2)$ and $61.7 \mathrm{MW}(15.4 \times 4)$. This is repeated for the $34.8 \%$ probability that $k$ is between 4 and 8 and the $0.2 \%$ probability that $k$ is between 8 and 16 . Each of the contributions spans two ranges of the final probability distribution, so the probability is split equally between each range. The contributions of range B and range $\mathrm{C}$ to the overall probability distribution are calculated in a similar manner and the contributions of all three ranges are summed to give the final probability distribution. The whole process is summarised in Table 2.

The derived probability distribution of the HRR of a HGV fire in a tunnel with $4 \mathrm{~ms}^{-1}$ longitudinal airflow is shown in Figure 12. The $10^{\text {th }}$ percentile of this distribution is approximately $34 \mathrm{MW}$, the $90^{\text {th }}$ percentile is approximately $151 \mathrm{MW}$ and the expectation, or mean, of the distribution is $71 \mathrm{MW}$.

Having derived the probability distribution for the ventilation velocity of interest, the model then adjusts the HRR range values in accordance with the value of the cargo factor input by the model user; the upper and lower HRR values for each of the ranges are simply multiplied by the cargo factor and divided by ten. Hence a cargo factor of ten will not alter the HRR at all, a lower value will reduce the HRR and a higher value will increase the HRR. The shape of the probability distribution remains unchanged by this operation.

The next thing the model does is to calculate the ventilation-controlled upper limit to the span of possible heat release rate values. The maximum sustainable heat release rate, $Q_{\max }$, for a given scenario can be calculated using:

$$
Q_{\max }=V \cdot \eta_{o x} \cdot \rho_{o x} \cdot \Delta H_{C o x} \mathrm{MW}
$$

where $V$ is the volumetric flow of air $\left(\mathrm{m}^{3} \mathrm{~s}^{-1}\right), \eta_{o x}$ is the proportion of oxygen in the airflow (generally 0.21 ), $\rho_{o x}$ is the density of oxygen $\left(1 \mathrm{kgm}^{-3}\right.$ at standard temperature and pressure) and $\Delta H_{C o x}$ is the 'heat of combustion for 
oxygen' which can be taken to have a value of about $13 \mathrm{kJg}^{-1}$ in most cases [28]. Thus, the maximum HRR of a fire in an enclosed space can generally be approximated by:

$$
Q_{\max }=2.73 \times V \mathrm{MW}
$$

For example, in a tunnel the size and shape of the Channel Tunnel with a longitudinal airflow of $4 \mathrm{~ms}^{-1}$ (averaged or uniform across the tunnel cross-section, i.e. a volumetric flow $\approx 180 \mathrm{~m}^{3} \mathrm{~s}^{-1}$ ), it is estimated that it is unlikely that the HRR of a fire will exceed 491MW for significant periods of time, as there would be expected to be insufficient oxygen for burning above this level. Higher peaks of HRR may be expected to occur in real tunnels as ventilation systems may not produce uniform flows of air or constant ventilation velocities. However, these peaks of HRR would not be expected to be sustained for long periods of time without additional ventilation.

Having established the upper limit of HRR, the model normalises the distribution so that the upper limit represents the $100^{\text {th }}$ percentile of the distribution. (Generally, when the upper limit does not correspond exactly to the upper end of one of the HRR ranges, the probability is assumed to be equally distributed within each range (on the $\log \mathrm{scale}^{\dagger}$ ) and the proportion of the probability falling above the upper limit is discounted accordingly.) In the example given above there is less than $1 \%$ probability of the HRR being above the upper HRR limit, hence the normalised probability distribution is not significantly different from the calculated one, shown in Figure 12.

Finally, the model calculates the critical HRR necessary to bring about fire spread to an adjacent HGV (a given distance away) and, based on the generated probability distribution, calculates the likelihood of the fire spreading by remote ignition (using FIRE-SPRINT A3). For example, the FIRE-SPRINT A3 model predicts that the critical HRR for fire spread to a HGV $5 \mathrm{~m}$ distant from the original fire is about $100 \mathrm{MW}$ for a ventilation velocity of $4 \mathrm{~ms}^{-1}$. Hence the likelihood of spread by remote ignition is about $47 \%$. These calculations assume that the control volume, and hence the horizontal flame section, in FIRE-SPRINT A3 extends $7.75 \mathrm{~m}$ along the length of the target HGV. If a shorter control volume is assumed (for example, extending only $3.875 \mathrm{~m}$ along the

\footnotetext{
${ }^{\dagger}$ The HRR ranges are of the form $2^{\text {n }}$ to $2^{\mathrm{n}+1}$, so the calculations are carried out on the $\log _{2} \operatorname{scale}$, but a $\log _{10}$ scale has been used on the graphs for clarity. The width of each range is equal on any log scale.
} 
target HGV), the calculated critical HRR for spread has a slightly smaller value (83 MW or $34 \%$ for the example given).

There is a great need to determine the conditions under which flame impingement occurs, and hence whether it is appropriate to use the results of the FIRE-SPRINT ' $\mathrm{A}$ ' models or those of the 'B' series models. It is intended that calculations assuming flame impingement (using FIRE-SPRINT 'B' series models) will be implemented in future versions of the model. It is also hoped that future versions of CERBERUS will be able to predict whether or not flame impingement will occur.

\section{SAMPLE RESULTS}

To demonstrate the use of the model, the likely outcomes of using different ventilation velocities on a fire involving a HGV in a tunnel similar in size to the Channel Tunnel have been evaluated.

A fire involving a HGV loaded with furniture, subject to a forced airflow velocity of $3 \mathrm{~ms}^{-1}$, would be expected to have a peak heat release rate between $36 \mathrm{MW}\left(10^{\text {th }}\right.$ percentile $)$ and $140 \mathrm{MW}\left(90^{\text {th }}\right.$ percentile $)$. The expectation of the probability distribution (which, in this case, is the same as the $50^{\text {th }}$ percentile) corresponds to a heat release rate of $71 \mathrm{MW}$. If the adjacent $\mathrm{HGV}$ were $4 \mathrm{~m}$ away there would be a $64 \%$ chance of the fire spreading (by remote ignition).

The probability of spread could be reduced to about $53 \%$ by increasing the separation distance to $10 \mathrm{~m}$ (ventilation remaining unchanged), or reduced to about $28 \%$ by increasing the ventilation rate to $10 \mathrm{~ms}^{-1}$ (vehicle spacing kept at $4 \mathrm{~m}$ ). However, if the ventilation rate were increased to $10 \mathrm{~ms}^{-1}$ and the separation were increased to $8 \mathrm{~m}$ or more, then the fire would not be expected to spread, according to the model. The heat release rate of the HGV fire in this case would range from $75 \mathrm{MW}\left(10^{\text {th }}\right.$ percentile $)$ to $425 \mathrm{MW}\left(90^{\text {th }}\right.$ percentile $)$ with the $50^{\text {th }}$ percentile being about 195MW. The expectation of the probability distribution, in this instance, is 190MW. Although the fire is not predicted to spread in this instance, heat release rates of this magnitude would be certain to do major damage to the tunnel lining and produce an extremely untenable environment for any tunnel users downstream of the fire location. 
Some sample results are shown in Figures 13 and 14.

In general it is observed that, although it will increase the HRR of the HGV fire, increasing the ventilation rate in the tunnel will tend to decrease the chances of the fire spreading to an adjacent vehicle by remote ignition. In most instances the fire would not be expected to spread at 9 or $10 \mathrm{~ms}^{-1}$ ventilation rates with vehicle separations of greater than $8 \mathrm{~m}$. It is, however, also observed that increasing the ventilation rate from about $4 \mathrm{~ms}^{-1}$ to $6 \mathrm{~ms}^{-1}$ will actually increase the chance of fire spread slightly, hence there is no advantage to using ventilation rates above $4 \mathrm{~ms}^{-1}$ unless very high ventilation velocities of about $8 \mathrm{~ms}^{-1}$ or greater are considered.

\section{DISCUSSION}

The results presented here show that, although longitudinal ventilation can greatly increase the severity of a fire (in terms of heat release rate) it does not necessarily increase the chance of the fire spreading to an adjacent HGV. Indeed, the chance of spread appears to tend to decrease with increasing ventilation velocity (assuming no flame impingement at all ventilation velocities).

In reality, whether or not flame impingement will occur on the target object will depend on separation distance, ventilation velocity and HRR. That is, to be able to fully assess the effect of varying the ventilation velocity or separation it becomes essential to know the conditions under which flame impingement will occur, and hence, for a given separation and ventilation velocity, whether it is appropriate to use the results of a FIRE-SPRINT 'A' series model or not.

To date, hardly any experimental studies on flame behaviour in tunnels have been carried out. Oka et al. [29,30] have published details of some small scale experiments on flame tilt and flame length from a burner in a longitudinally ventilated wind tunnel. Their results indicate a relationship between the angle of flame tilt, $\theta_{1}$, and $v / U^{*}$, where $v$ is the longitudinal airflow in the tunnel and $U^{*}$ is the "characteristic upward velocity" of the flames which is related to the HRR of the fire. From their results it is apparent that for values of $v / U^{*}$ less than 
about 0.3 , the flames are deflected by less than $45^{\circ}$ from vertical and for values of $v / U^{*}$ greater than about 0.5 , the flames are deflected by more than $70^{\circ}$ from vertical.

Assuming that a $45^{\circ}$ flame tilt would cause the flames to significantly impinge on a HGV $5 \mathrm{~m}$ distant, that a $70^{\circ}$ flame tilt would cause the flames to significantly impinge on a HGV 10m distant and that the same relationships hold for a full scale tunnel, it would mean that the flames from a 10MW fire would impinge on a HGV 5m away at ventilation velocities above about $2 \mathrm{~ms}^{-1}$ and would impinge on a HGV $10 \mathrm{~m}$ away at velocities above about $4 \mathrm{~ms}^{-1}$. Similarly, if the fire were 50MW then ventilation velocities of 3 and $4 \mathrm{~ms}^{-1}$ would be required for flame impingement at 5 and $10 \mathrm{~m}$ respectively. The corresponding ventilation velocities would be about 4 and $6 \mathrm{~ms}^{-1}$ if the fire size was $100 \mathrm{MW}$ and 5 and $7 \mathrm{~ms}^{-1}$ at $200 \mathrm{MW}$.

The authors are aware of the danger of extrapolating relationships from model scale experiments to full scale tunnels. At present, these correlations are untested and are only presented to demonstrate the importance of fire spread by flame impingement.

Work is continuing on the CERBERUS and FIRE-SPRINT models and it is intended to investigate the mechanism of fire spread by flame impingement and include the results in future versions of the models.

\section{Use of the Results}

In practical terms, fire is a non-deterministic process and two seemingly identical fires may behave differently under ostensibly identical conditions. CERBERUS is a non-deterministic model and, instead of predicting a single HRR for a HGV fire under given conditions, it estimates the probability distribution of HRR. The results from the current model may be used in a number of ways. One possible use of the results is in the design process; different emergency ventilation strategies may be considered and the ventilation rate which results in a relatively low probability of spread may be found. Alternatively, the model may be used to assess the effect of changing vehicle spacing in situations like the HGV carrier wagons used in the Channel Tunnel. It is vital to remember, however, that the present model assumes spread by remote ignition. 
Another possible use of the model would be to estimate input values for Computational Fluid Dynamics (CFD) and other models. Simulation of fires in tunnels using CFD models has become extremely widespread in recent years. Indeed, virtually every tunnel construction project in the last five to ten years is likely to have included an analysis of some fire scenarios using CFD software at the design stage. The results of these models can be a great aid in the design of ventilation systems etc. However, in the majority of these CFD simulations, the HRR of the initial fire would have been input by the user and would not have varied under different ventilation conditions unless the user altered it manually. The accuracy of CFD model outputs is therefore directly related to the reliability of the HRR input by the user; amongst other things.

CFD models are deterministic in nature. For a given set of inputs, the models will always give the same set of output values. In order to model the non-deterministic nature of fires in tunnels, CFD and other model users are urged to consider the results of the CERBERUS model before running any simulations of fires in tunnels. The probabilistic results of this study show a spread of possible fire behaviour, given the assumptions made. Although the model is based on specific assumptions which represent only an approximation of any given realworld case, it serves to give an indication of the possible range of HRR values which might exist in a tunnel fire.

When carrying out CFD or other simulations of tunnel fires, users are encouraged to run their model for a range of HRR values; in addition to sensitivity studies. In this way their simulations will demonstrate a span of possible fire scenarios, not merely one. For example, simulations could be based on the $10^{\text {th }}, 50^{\text {th }}$ and $90^{\text {th }}$ percentiles from the probability distribution produced by CERBERUS.

\section{CONCLUSIONS}

The probabilistic model described in this paper calculates that:

- The heat release rate of a $\mathrm{HGV}$ fire in a tunnel increases dramatically with increasing longitudinal ventilation velocity.

- The probability of the fire spreading to an adjacent HGV tends to decrease with increasing ventilation velocity. However, this assumes that flame impingement does not occur on the target HGV. 
It should be noted that the model is not able to estimate whether flame impingement will occur or not and is not yet able to estimate the probability of spread if flame impingement does occur..

\section{ACKNOWLEDGEMENTS}

The projects described in this paper were funded by the Engineering \& Physical Sciences Research Council under grants GR/J44506, GR/L69732, GR/N16761 and GR/R46502. 


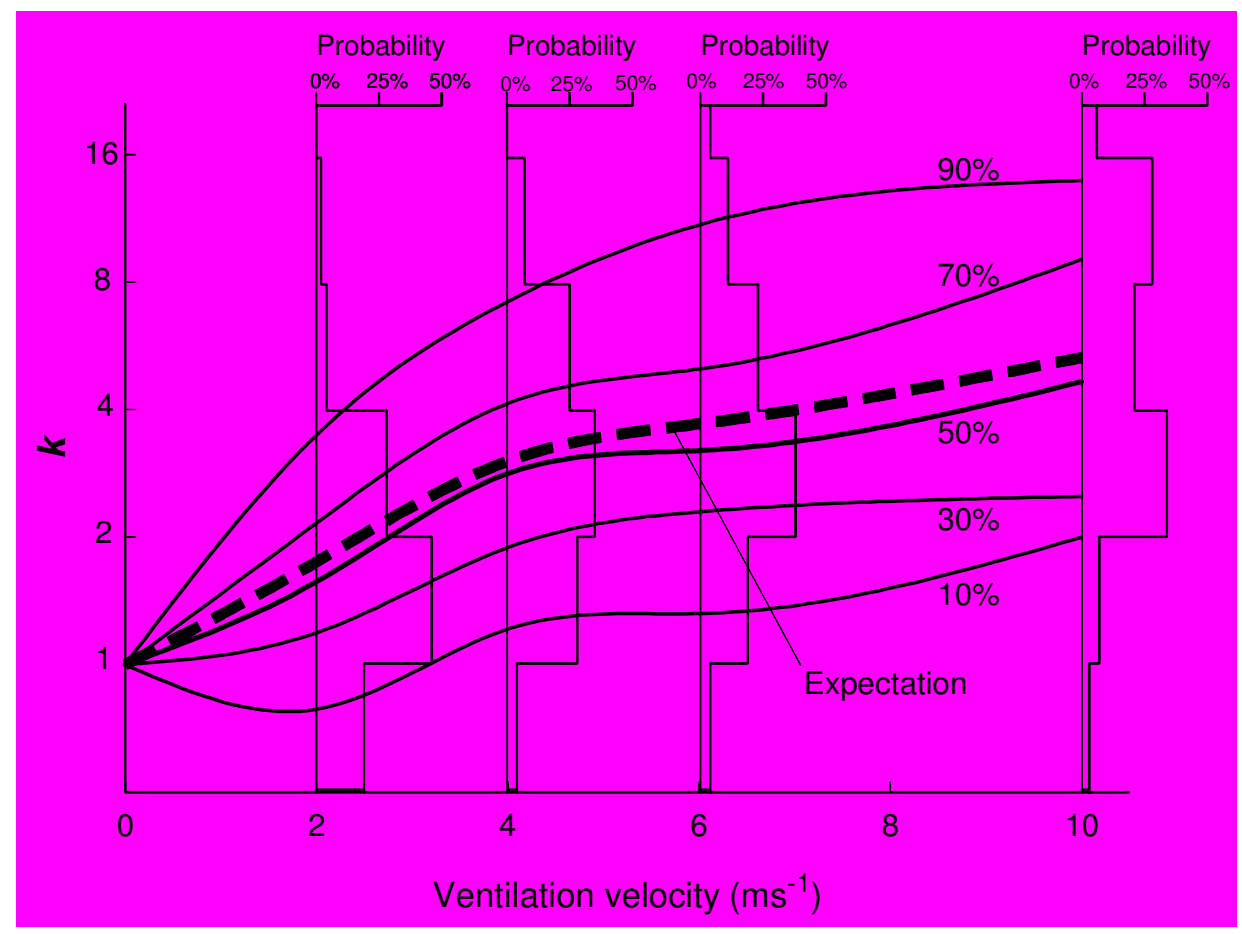

Figure 1 - The prior probability data for a HGV fire in a tunnel, similar to the Channel Tunnel, subject to forced longitudinal ventilation, based on expert estimates. The calculated data are represented by the step graphs at 2,4 , 6 and $10 \mathrm{~ms}^{-1}$. The expectation values are represented by the broken line. The continuous probability percentiles shown have been inferred from the discrete probability distributions and merely represent trends in the data. 


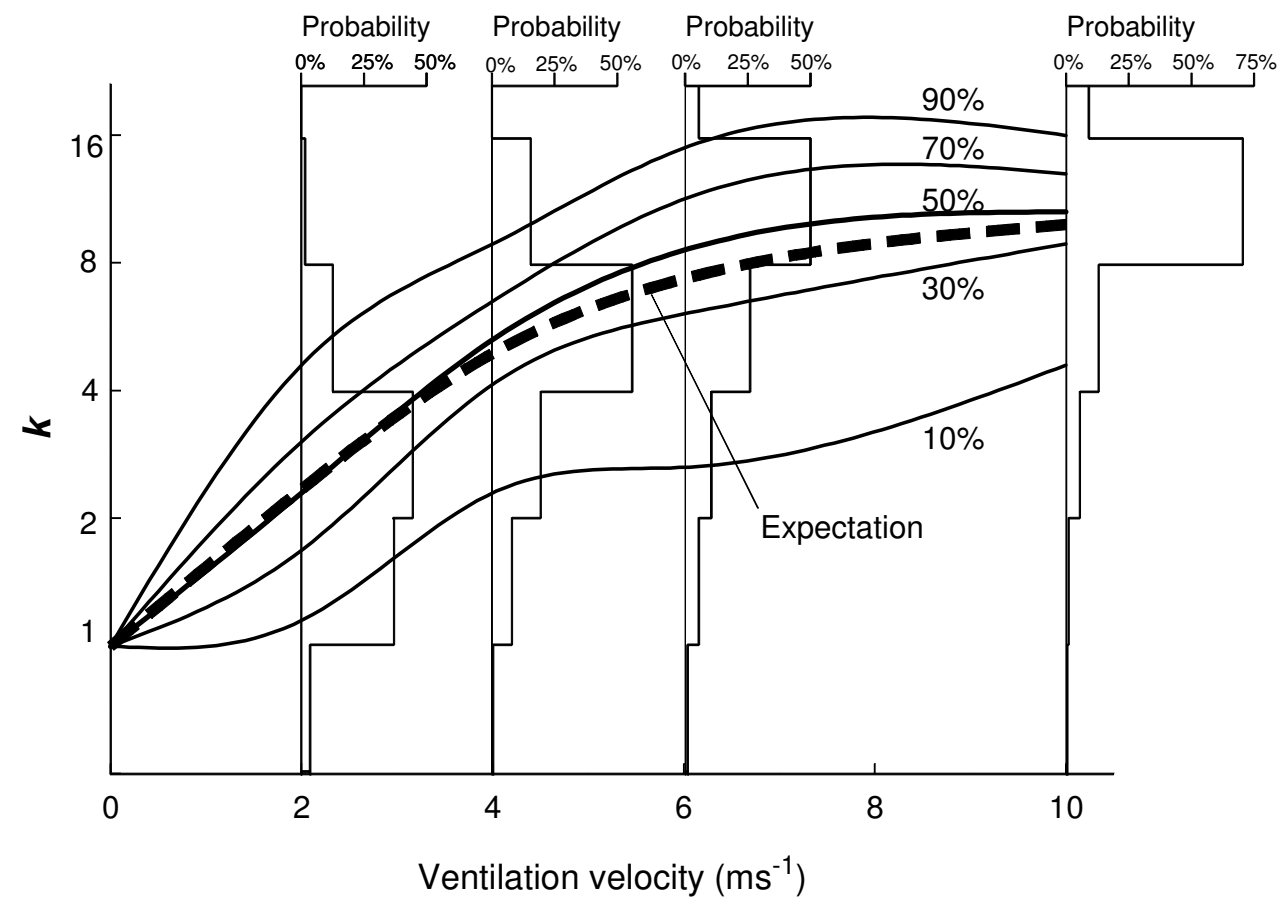

Figure 2 - The results from the original study: Posterior probability data for a HGV fire in a tunnel, similar to the Channel Tunnel, subject to forced longitudinal ventilation. The calculated data are represented by the step graphs at 2, 4, 6 and $10 \mathrm{~ms}^{-1}$. The expectation values are represented by the broken line. The continuous probability percentiles shown have been inferred from the discrete probability distributions and merely represent trends in the data. 


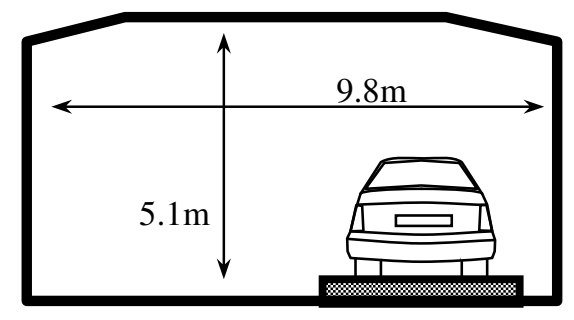

Figure 3 - Diagram of the 2nd Benelux tunnel

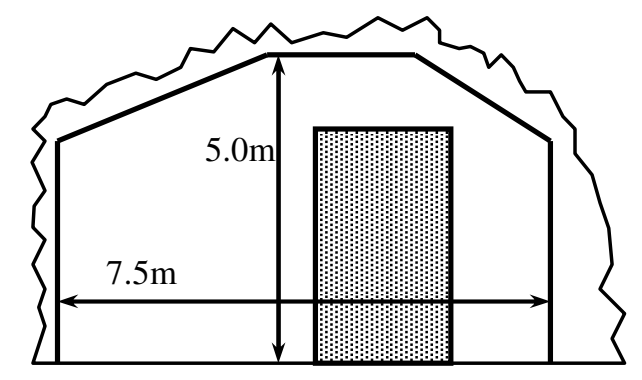

Figure 4 - Diagram of the Runehamar tunnel 


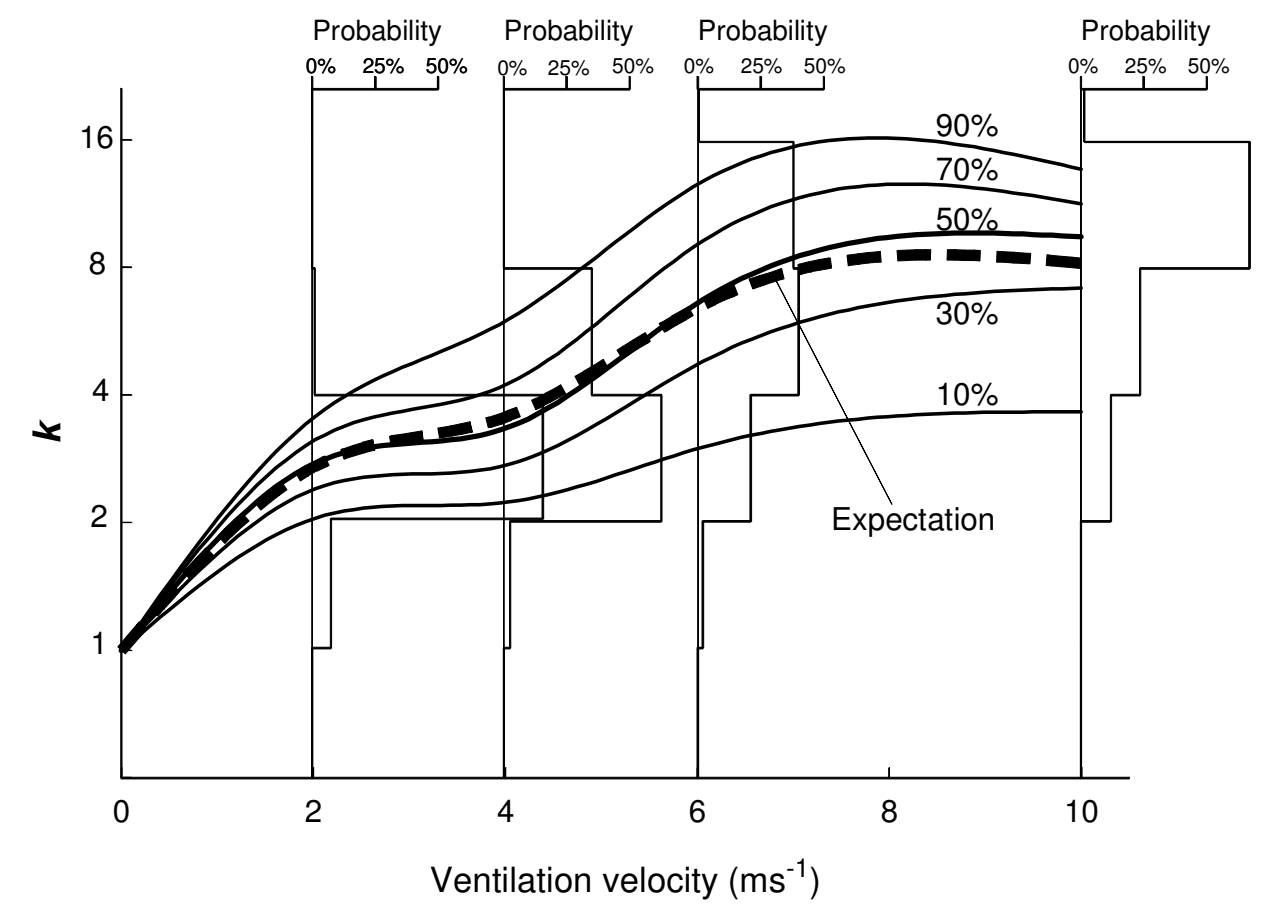

Figure 5 - The updated results: Final posterior probability data for a HGV fire in a tunnel, similar to the Channel Tunnel, subject to forced longitudinal ventilation. The calculated data are represented by the step graphs at 2, 4, 6 and $10 \mathrm{~ms}^{-1}$. The expectation values are represented by the broken line. The continuous probability percentiles shown have been inferred from the discrete probability distributions and merely represent trends in the data. 

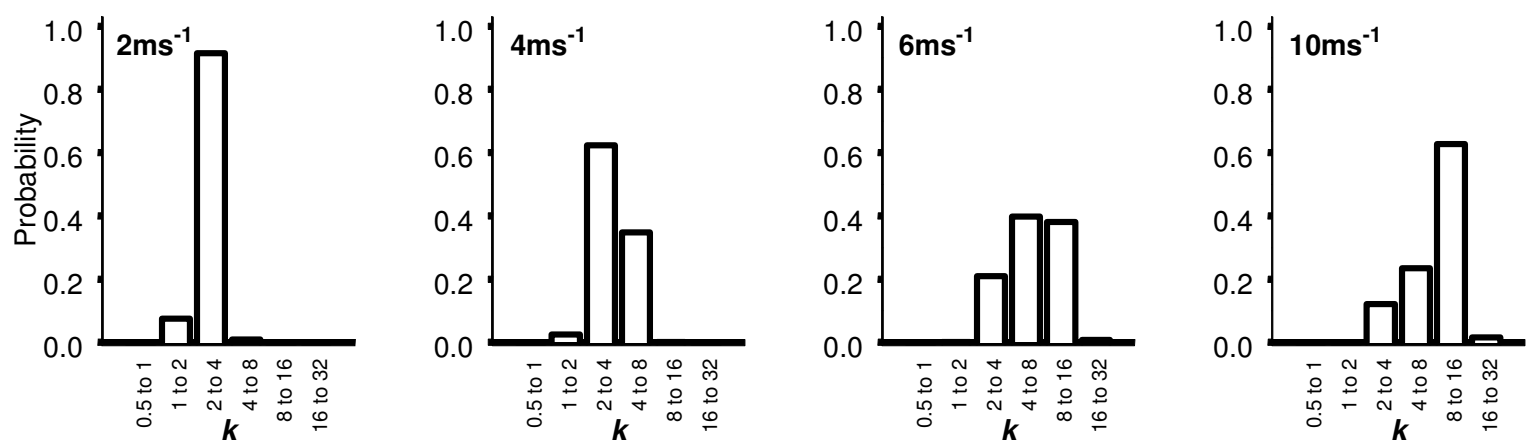

Figure 6 - Posterior probability distributions of $k$ for a fully involved HGV fire in a single-lane tunnel, similar to the Channel Tunnel.

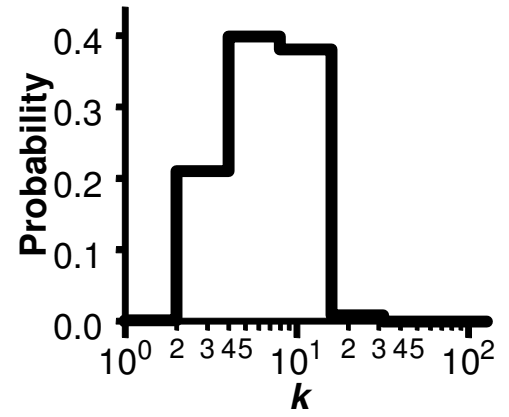

(a)

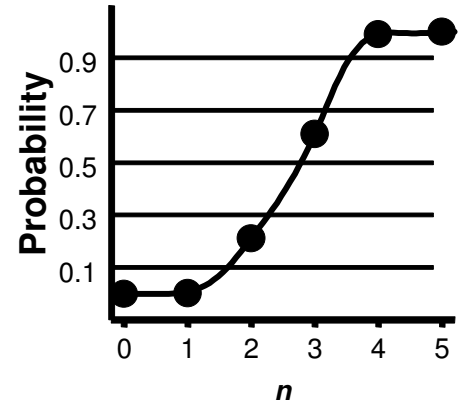

(b)

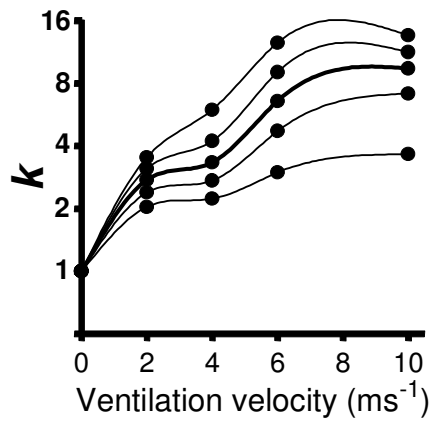

(c)

Figure 7 - Calculating the probability percentile values for a HGV fire at $6 \mathrm{~ms}^{-1}$ : (a) the probability distribution of $k$ at $6 \mathrm{~ms}^{-1}$, (b) the same data expressed as a cumulative probability distribution of $n$ (where $k=2^{n}$ ), (c) the derived percentile graphs. 


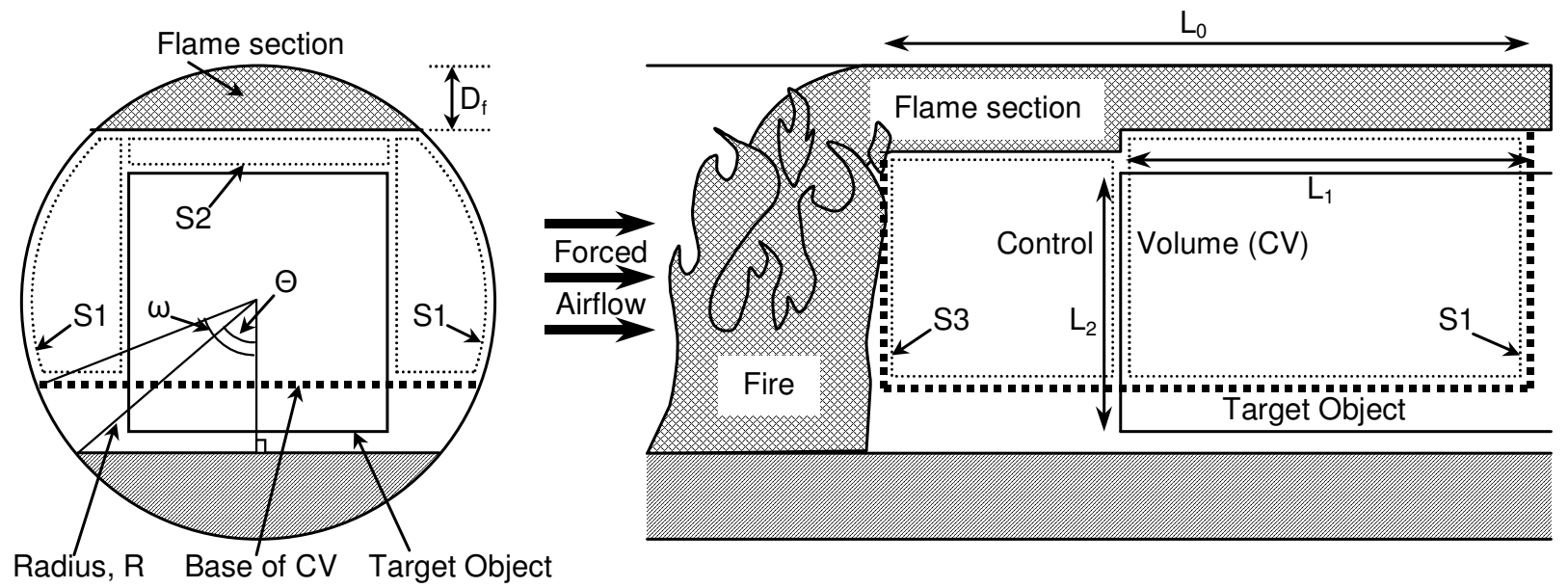

Figure 8 - Diagram of the tunnel considered by the FIRE-SPRINT A3 model.

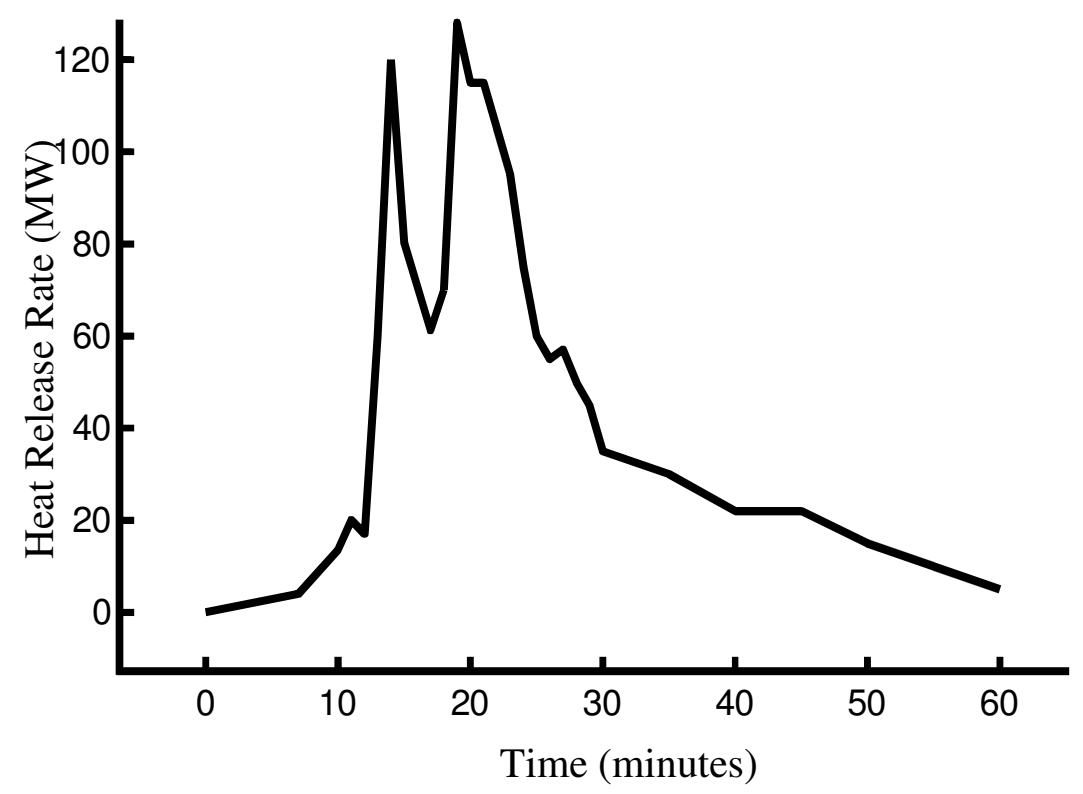

Figure 9 - The variation of heat release rate with time for the Hammerfest HGV test. Data calculated by the Unit of Fire Safety Engineering, University of Edinburgh, on behalf of Eurotunnel Plc. 


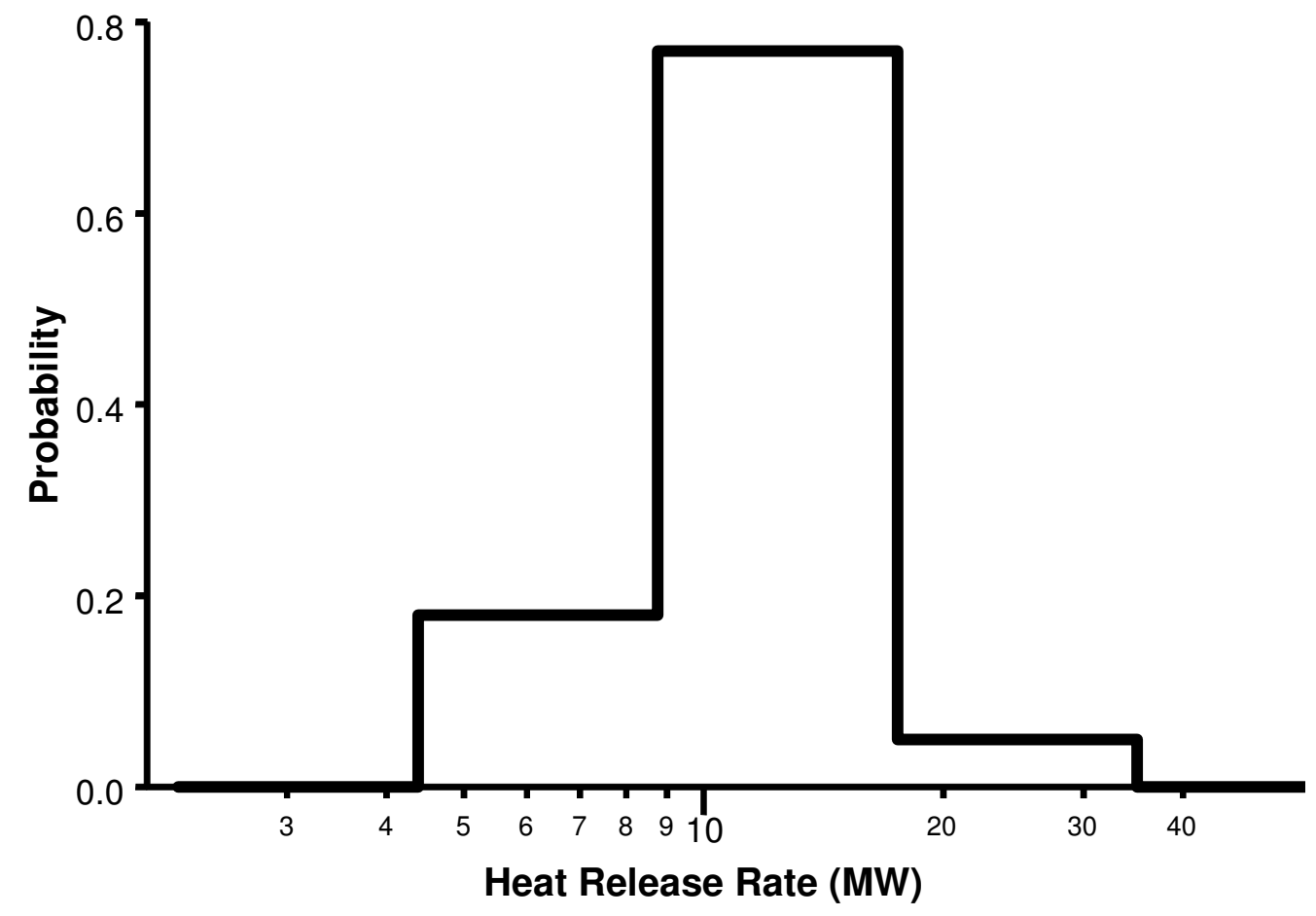

Figure 10 - Probability distribution for a HGV fire (with a cargo of furniture) in the open air. 


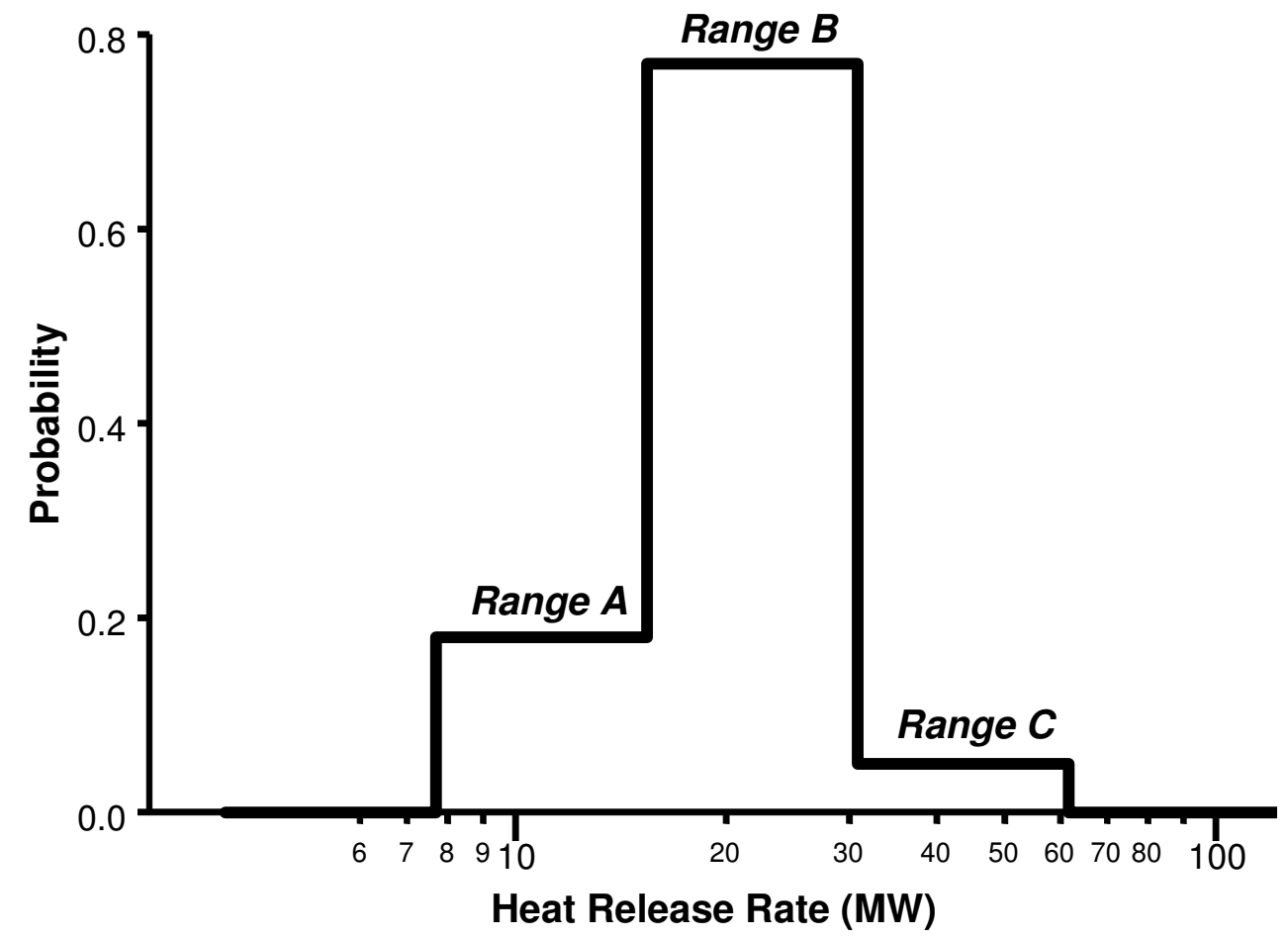

Figure 11 - Probability distribution for a HGV fire (with a cargo of furniture) in a tunnel similar to the Channel Tunnel, subject to natural ventilation. 


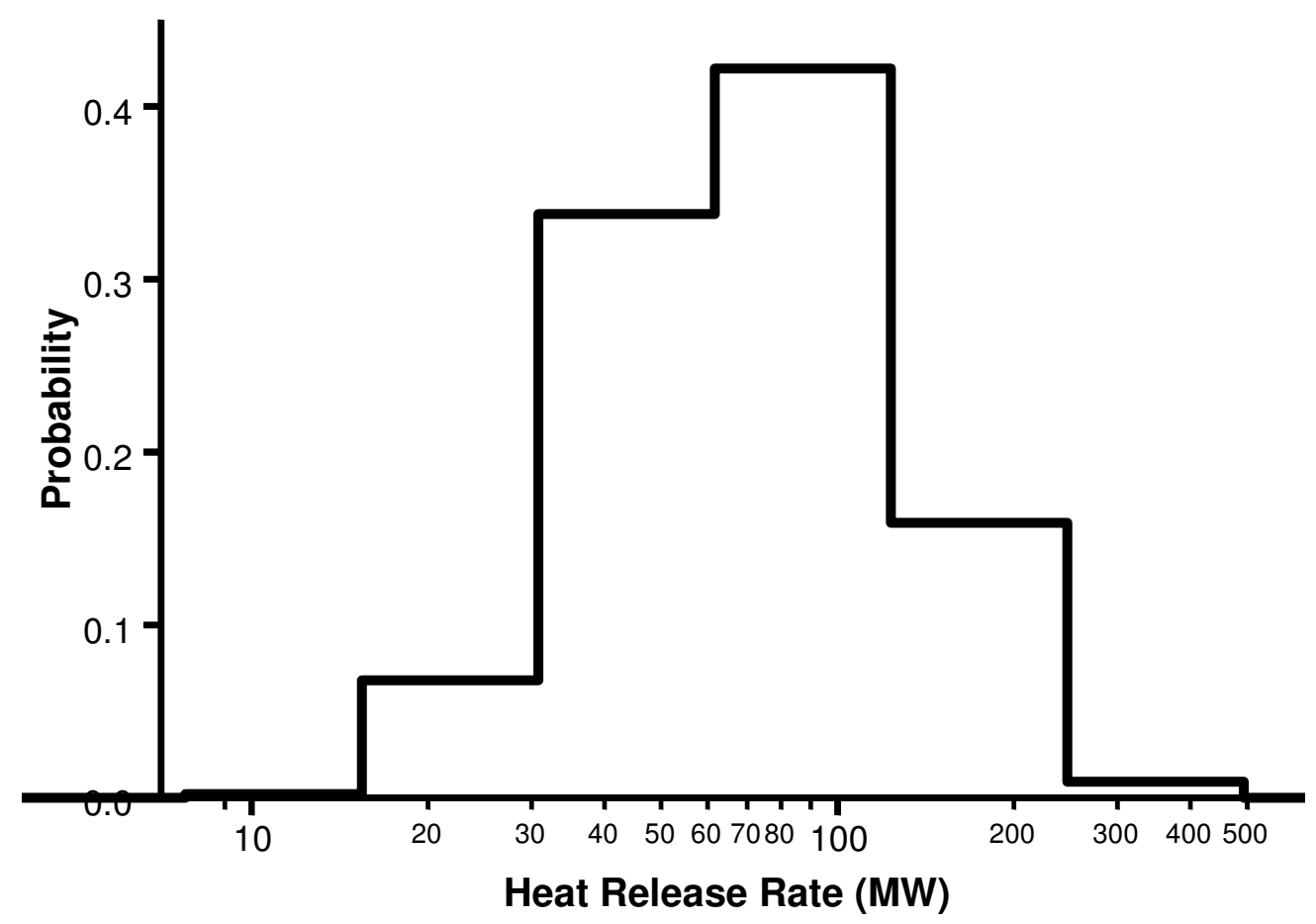

Figure 12 - Example: Probability distribution of the HRR of a HGV fire (with a cargo of furniture) in a tunnel, similar to the Channel Tunnel, with $4 \mathrm{~ms}^{-1}$ longitudinal airflow. 


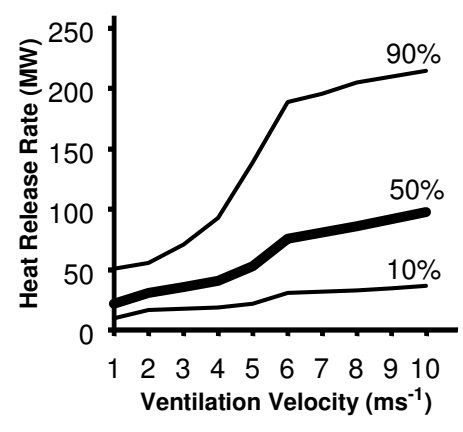

(a)

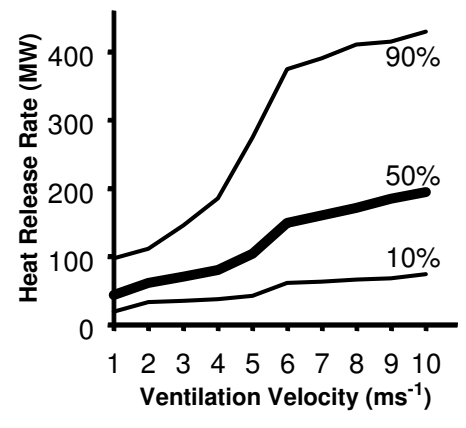

(b)

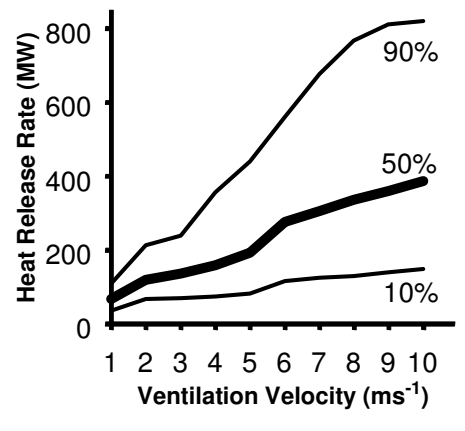

(c)

Figure 13 - HRR vs. forced longitudinal ventilation for a HGV with a cargo factor of (a) 5, (b) 10 and (c) 20.

The data are expressed as graphs of the $10^{\text {th }}, 50^{\text {th }}$ and $90^{\text {th }}$ probability percentiles of HRR against ventilation velocity.

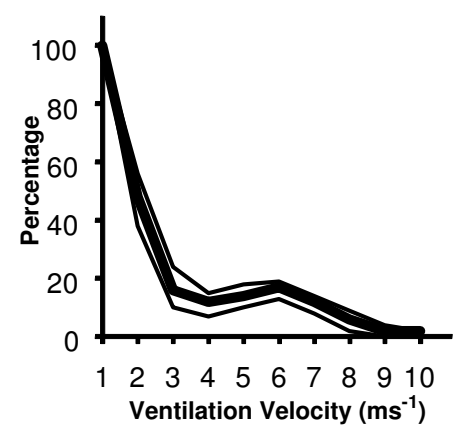

(a)

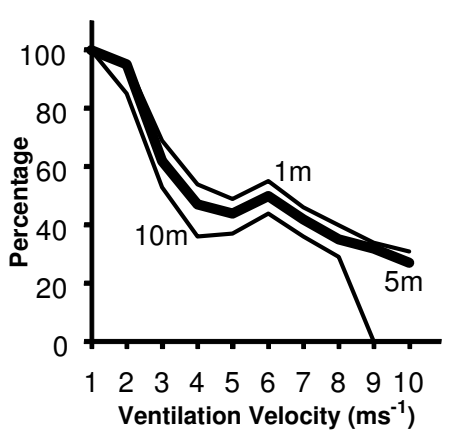

(b)

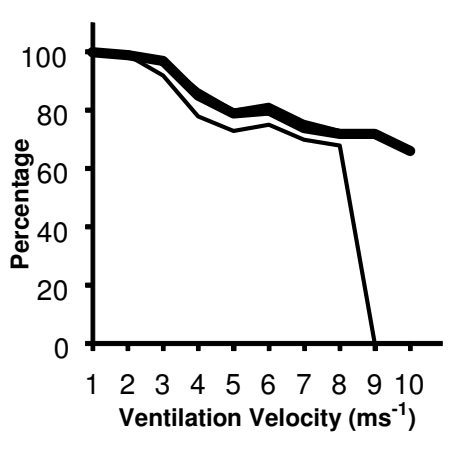

(c)

Figure 14 - Probability of spread (by remote ignition) for a HGV with a cargo factor of (a) 5, (b) 10 and (c) 20 , for vehicle spacings of 1,5 and $10 \mathrm{~m}$. (Note: the $1 \mathrm{~m}$ and $5 \mathrm{~m}$ spacing lines on graph (c) are indistinguishable) 
Table 1 - Percentage probabilities of $k$ for ventilation velocities of 2, 3 and $4 \mathrm{~ms}^{-1}$ in a single lane tunnel (- indicates a negligible, but non-zero, probability).

\begin{tabular}{ccccccccc}
\hline$k$ & $0.5-1$ & $1-2$ & $2-4$ & $4-8$ & $8-16$ & $16-32$ & $32-64$ & $64+$ \\
\hline $2 \mathrm{~ms}^{-1}$ & - & $7.5 \%$ & $91.5 \%$ & $1.0 \%$ & - & - & - & - \\
$3 \mathrm{~ms}^{-1}$ & - & $5.0 \%$ & $76.9 \%$ & $17.9 \%$ & $0.1 \%$ & - & - & - \\
$4 \mathrm{~ms}^{-1}$ & - & $2.5 \%$ & $62.4 \%$ & $34.8 \%$ & $0.2 \%$ & - & - & - \\
\hline
\end{tabular}




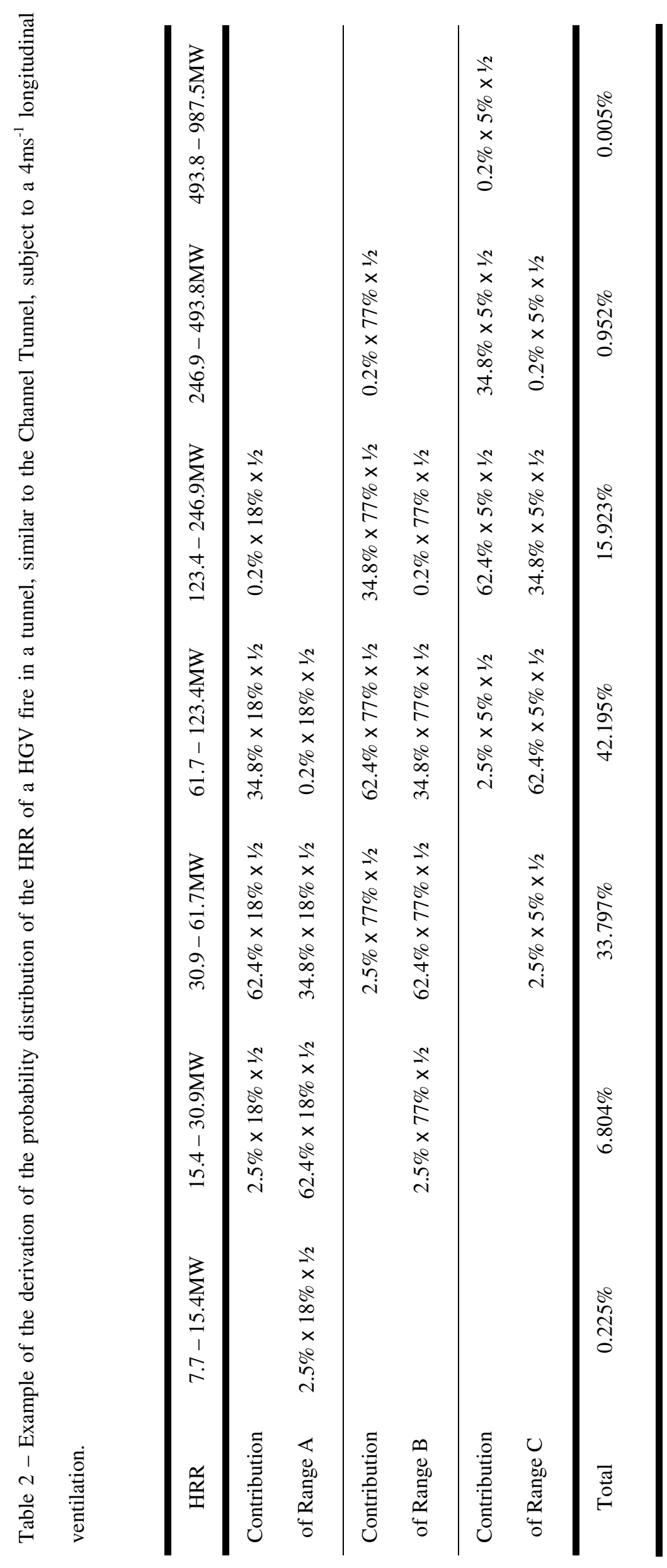




\section{REFERENCES}

1 Burns, D. (2003) External Observations of the Daegu underground railway/metro Fire Disaster $18^{\text {th }}$ February 2003. Proc. $5^{\text {th }}$ Int. Conf. on Safety in Road and Rail Tunnels, Marseille, France, 6-10 October 2003 (Ed. A.E. Vardy). pp. 13-26. Published by Tunnel Management International and the University of Dundee.

2 Henke, A. and Gagliardi, M. (2003) The 2001 Gotthard Fire: Response of the system, behaviour of the users. How was the fast reopening of the tunnel possible? Proc. $5^{\text {th }}$ Int. Conf. on Safety in Road and Rail Tunnels, Marseille, France, 6-10 October 2003 (Ed. A.E. Vardy). pp. 3-12. Published by Tunnel Management International and the University of Dundee.

3 Schupfer, H. (2001) Fire Disaster in the Tunnel of the Kitzsteinhorn Funicular in Kaprun on 11 Nov. 2000. Presented at $4^{\text {th }}$ Int. Conf. on Safety in Road and Rail Tunnels, Madrid, Spain, 2-6th April 2001. Paper not in proceedings.

4 Brichet, N., Weatherill, A., Crausaz, B. \& Casale, E. (2002) The new ventilation systems of the Mont Blanc Tunnel active smoke control: From simulation to successful operation. Proc. of the $4^{\text {th }}$ Int. Conf. on Tunnel Fires, Basel, Switzerland, 2-4 December 2002. pp. 95-104. ITC Conferences Ltd, ISBN 1901808211

5 Memorial Tunnel Fire Ventilation Test Programme (1996). Interactive CD-ROM \& Comprehensive Test Report. Parsons Brinckerhoff 4D Imaging.

6 Babrauskas, V. and Peacock, R.D. (1992) Heat Release Rate: The single most important variable in fire hazard. Fire Safety Journal, 18: 255-272.

7 Carvel, R.O., Beard, A.N., Jowitt, P.W. and Drysdale, D.D. (2001) Variation of Heat Release Rate with Forced Longitudinal Ventilation for Vehicle Fires in Tunnels. Fire Safety Journal, 36: 569-596.

8 Carvel, R.O., Beard, A.N. \& Jowitt, P.W. “A Bayesian estimation of the effect of forced ventilation on a pool fire in a tunnel” Civil Engineering \& Environmental Systems, Volume 18 (2001) pp. 279-302

9 Carvel, R.O., Beard, A.N. and Jowitt, P.W. (2001) The influence of longitudinal ventilation systems on fires in tunnels. Tunnelling \& Underground Space Technology, 16: 3-21

10 Beard, A.N., Drysdale, D.D. and Bishop, S.R. (1995) A non-linear model of major fire spread in a tunnel. Fire Safety Journal, 24: 333-357.

11 Beard, A.N. (1997) A model for predicting fire spread in tunnels. Journal of Fire Sciences, 15: 277-307. 
12 Beard, A.N. (2001) Major fire spread in a tunnel: A non-linear model. Proc. $4^{\text {th }}$ Int. Conf. on Safety in Road and Rail Tunnels, 2-6 April 2001, Madrid, Spain (Ed. A.E. Vardy). pp. 467-476. Published by Independent Technical Conferences Ltd and the University of Dundee.

13 Beard, A.N. (2003) Major fire spread in a tunnel: A non-linear model with flame impingement. Proc. $5^{\text {th }}$ Int. Conf. on Safety in Road and Rail Tunnels, Marseille, France, 6-10 October 2003 (Ed. A.E. Vardy). pp. 511-521. Published by Tunnel Management International and the University of Dundee.

14 Martin, J-C., Delémont, O. and Calisti, C. (2004) Fire in the St. Gotthard road tunnel. The Handbook of Tunnel Fire Safety (Ed. R. Carvel \& A. Beard), Thomas Telford, London, 2004. (in press)

15 Lacroix, D. (2001) The Mont Blanc Tunnel Fire: what happened and what has been learned. Proc. $4^{\text {th }}$ Int. Conf. on Safety in Road and Rail Tunnels, 2-6 April 2001, Madrid, Spain (Ed. A.E. Vardy). pp. 3-16. Published by Independent Technical Conferences Ltd and the University of Dundee.

16 Quintiere, J.G. (1989) Scaling applications in fire research. Fire Safety Journal, 15: 3-29.

17 Wu, Y., Bakar, M.Z.A., Atkinson, G.T. and Jagger, S. (1997) A study of the effect of tunnel aspect ratio on control of smoke flow in tunnel fires. $9^{\text {th }}$ Int. Conf. on Aerodynamics and Ventilation of Vehicle Tunnels, Aosta Valley, Italy, October 6-8 1997 pp. 573-587

18 Malhotra, H.L. (1995) Goods Vehicle Fire Test in a Tunnel. Proc. $2^{\text {nd }}$ Int. Conf. Safety in Road and Rail Tunnels, Granada, Spain 1995 (Ed. A.E. Vardy). pp. 237-244. Published by Independent Technical Conferences Ltd and the University of Dundee.

19 Fires in Transport Tunnels: Report on full-scale tests. (1995) EUREKA-Project EU499:FIRETUN Studiengesellschaft Stahlanwendung elV. D-40213 Dusseldorf.

20 Bettis, R J, Jagger, S F and Moodie, K. (1994) Reduced scale simulations of fires in partially blocked tunnels. Proc. Int. Conf. on Fires in Tunnels, Borås, Sweden, October 10-11, 1994. pp. 163-186. Published by SP Fire Technology, Sweden.

21 Bettis, R.J., Wu, Y. and Hambleton, R.T. (1993) Interim Validation of Tunnel Fire Consequence Models: Data from phase 2, Test 5. Section paper IR/L/93/09 (part 5). Health \& Safety Executive, Buxton.

22 Ingason, H, Nireus, K and Werling, P. (1997) Fire tests in a blasted rock tunnel. Report FOA-R-9700581-990-SE. FOA, Sweden. 
23 Project 'Safety Test' - Report on Fire Tests (2002). Directorate-General for Public Works and Water Management, Civil Engineering Division, Utrecht, The Netherlands, August 2002 (available from www.minvenw.nl)

24 Ingason, H. (2003) Proceedings of the International Conference on Catastrophic Tunnel Fires, Borås, Sweden, 20-2 $1^{\text {st }}$ November 2003. Published by SP Fire Technology, Sweden.

25 Carvel, R.O., Beard, A.N. and Jowitt, P.W. (2003) The influence of longitudinal ventilation on fire size in tunnels: update. Proc. $5^{\text {th }}$ Int. Conf. on Safety in Road and Rail Tunnels, Marseille, France, 6-10 October 2003 (Ed. A.E. Vardy). pp. 431-441. Published by Tunnel Management International and the University of Dundee.

26 Carvel, R.O., Beard, A.N. and Jowitt, P.W. (2001) How much do tunnels enhance the heat release rate of fires? Proc. $4^{\text {th }}$ Int. Conf. on Safety in Road and Rail Tunnels, 2-6 April 2001, Madrid, Spain (Ed. A.E. Vardy). pp. 457-466. Published by Independent Technical Conferences Ltd and the University of Dundee.

27 Carvel, R.O., Beard, A.N. and Jowitt, P.W. (2001) A method for estimating the heat release rate of a fire in a tunnel. Proc. $3^{\text {rd }}$ Int. Conf. on Tunnel Fires, Gaithersburg, Maryland, 9-11 $1^{\text {th }}$ October 2001, pp. 137-144. Published by Tunnel Management International.

28 Drysdale, D.D. (1999) Introduction to Fire Dynamics. $2^{\text {nd }}$ Edition. John Wiley and Sons, Chichester.

29 Oka, Y., Yamada, T., Kurioka, H., Sato, H., Kuwana, H. and Sugawa, O. (1998) Flame behaviour in a

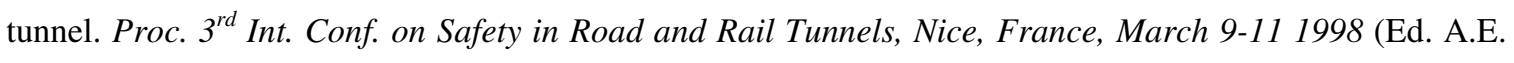
Vardy). pp. 159-168. Published by Independent Technical Conferences Ltd and the University of Dundee.

30 Kurioka, H., Oka, Y., Satoh, H. and Sugawa, O. (2003) Fire properties in near field of square fire source with longitudinal ventilation in tunnels. Fire Safety Journal, 38: 319-340. 